61 Molecular Biology and Genetics Unit, Jawaharlal Nehru Centre for Advanced Scientific

7 Research, Jakkur P. O., Bangalore 560064

\section{Identification of PAX6 and NFAT4 as the transcriptional regulators of IncRNA Mrhl in} neuronal progenitors

Running title: Mrhl transcription regulation in NPC

Debosree Pal ${ }^{1,2^{*}}$, Sangeeta Dutta ${ }^{1 *}$, Dhanur P Iyer ${ }^{1,3}$, Utsa Bhaduri ${ }^{1,4}$, M.R.S Rao ${ }^{1, \#}$

2 Present address: Blizard Institute, Barts and the London School of Medicine and Dentistry, Queen Mary University of London, London E1 2AT

3 Present Address: Department for Genome Regulation, Max Planck Institute for Molecular Genetics, Ihnestraße 63-73, Berlin, Germany - 14195.

4 Present address: Department of Life Sciences, University of Trieste, Trieste, Italy, and EU H2020 TRIM-NET ITN, Marie Sklodowska-Curie Actions (MSCA)

\# Address of correspondence to: Prof. M.R.S.Rao at Molecular Biology and Genetics Unit, Jawaharlal Nehru Centre for Advanced Scientific Research, Jakkur P. O., Bangalore 560064, India. Tel.: 91-80-2208-2864; Fax: 91-80-2362-2762; E-mail: mrsrao@jncasr.ac.in

* These authors have contributed equally

Keywords: Mrhl, LncRNA, NPCs, Transcription factor, Brain, PAX6 
26

27

28

29

30

31

\section{Summary statement}

Transcriptional regulation of lncRNA Mrhl by multiple lineage-specific transcription factors in neuronal progenitors highlights context-dependent regulation important for lineage specification.

\section{Abstract}

LncRNA Mrhl has been shown to be involved in regulating meiotic commitment of mouse spermatogonial progenitors and coordinating differentiation events in mouse embryonic stem cells. Here we have characterized the interplay of Mrhl with lineage-specific transcription factors during mouse neuronal lineage development. Our results demonstrate that Mrhl is predominantly expressed in the neuronal progenitor populations in mouse embryonic brains and in retinoic acid derived radial-glia like neuronal progenitor cells. Mrhl levels are significantly down regulated in postnatal brains and in maturing neurons. In neuronal progenitors, a master transcription factor, PAX6, acts to regulate the expression of Mrhl through direct physical binding at a major site in the distal promoter, located at $2.9 \mathrm{~kb}$ usptream of the TSS of Mrhl. Furthermore, NFAT4 occupies the Mrhl proximal promoter at two sites, at 437bp and 143bp upstream of the TSS. ChIP studies reveal that PAX6 and NFAT4 interact with each other, suggesting co-regulation of lncRNA Mrhl expression in neuronal progenitors. Our studies herewith are crucial towards understanding how lncRNAs are regulated by major lineage-specific TFs towards defining specific development and differentiation events.

(1) 


\section{Introduction}

Non-coding RNA dominates the eukaryotic transcriptome contributing up to $80-90 \%$ of it (Zhang et. al., 2019 a). Long non-coding RNAs (lncRNA) are classified as a major class of non-coding RNAs with a length greater than 200 nucleotides, without any or little translational activity (Wilusz et. al. 2009; Jarroux et. al., 2017). LncRNAs which do show little translational activity has been reported to possess small open reading frame which encodes for small or micro peptides of fundamental biological importance (Hartford \& Lal, 2020; Xing et. al., 2020). Although most of the long non-coding RNAs (lncRNAs) are not well conserved, their highly specific spatial-temporal expression has highlighted their complex roles in diverse biological functions during development and differentiation. And their dysregulation has been associated with several diseases including cancer and neurological disorders (Iyer et. al., 2015; Kopp \& Mendell, 2018; Marchese et. al., 2017; Wapinski \& Chang, 2011; Sun \& Kraus, 2015; Li et. al., 2019). Several studies have verified the importance of long non-coding RNAs as functional regulators. To regulate their targets LncRNAs are known to use a wide variety of mechanisms both at transcriptional and post transcriptional levels (Chen \& Tergaonkar, 2020; Rosa \& Ballarino, 2016; Yoon et. al., 2013; Akhade et. al., 2017).

During development of a mammalian system, a synchronous expression and repression of genes leads to a staggering variety of cells with various functional activities. This remarkable orchestration of genetic component is most evident in an extremely complex system of mammalian neural development and brain with its intricate cellular architecture, maintenance and function. However, regulators behind this fine coordination are still elusive. With a large number of highly specific lncRNAs expressed in the brain, their contribution in neuronal development is undeniable (Zhao et. al., 2020; Roberts et. al., 2014; Briggs et. al., 2015; Hart \& Goff, 2016; Mercer et. al., 2008; Derrien et. al., 2012; Kadakkuzha et. al., 2015). Data from GENCODE v 7 catalog suggest $40 \%$ of most differentially expressed lncRNAs are specific for brain (Derrien et. al., 2012). A notable aspect is their distinct neuroanatomical loci along with developmental and stage specific expression as evident in many studies (Liau et. al., 2021; Lv et. al., 2013; Antoniou et. al., 2014; Dinger et. al., 2008; Mohamed et. al., 2010; Hezroni et. al., 2020). For example, in a study by Goff. et. al., they used mutant mouse models for 13 lncRNAs (Lincenc1, Eldr, Pantr1, Pantr2, Tug1, Peril etc.) and assessed their expression pattern from E14.5 to adult brain revealing high variability in expression pattern for each lncRNA both spatially and temporally (Goff et. al., 2015). Along with characteristic lncRNA expression signatures in sub-regions of the brain and specific neuronal populations, studies 
have also shown lncRNA-mRNA pairs, sharing a genomic locus, to be displaying specific coexpression in a region-specific manner. For example, lncRNA GM9968 and DNA binding protein gene Zbtb20 show high enrichment in hippocampus (Kadakkuzha et. al., 2015). Transcriptome analysis by Lv. et. al. has revealed the development stage specificity of lncRNAs in mouse (Lv et. al., 2013). They have annotated large number of lncRNAs to the embryonic brain. Interestingly they found that expression of most them were very low or nonevident in the adult brain, suggesting their significance during embryonic brain development (Lv et. al., 2013).

LncRNAs have been shown to undergo regulated expression during development and differentiation (Fullard et. al., 2018). Studies have verified dynamic expression and regulation of many lncRNAs in conjunction with stage-specific transcription factors (TFs) during in-vitro differentiation scenarios like of mouse embryonic stem (ES) cells to embryoid bodies (EB) or during retinoic acid mediated neuronal differentiation of ES cells (Antoniou et. al., 2014; Dinger et. al., 2008). Observations from these studies indicate association of pluripotent factors like SOX2, OCT4 and NANOG at the promoter of lncRNAs, modulating their expression during development. For example, lncRNA AK028326 is activated by OCT4 while lncRNA AK141205 is repressed by NANOG resulting in the modulation of mouse ES cell pluripotency (Mohamed et. al., 2010). This tightly controlled differential expression pattern of lncRNAs is thus important for the delicate balance between lineage commitment and maintenance of pluripotent status. Results from loss and gain of function studies involving lncRNAs also show the vice versa to be true. Knockdown and over expression of lncRNAs alters the expression of transcription factors regulating them, leading to disruption of lineage specification. For example, using inducible knockdown of lncRNAs Rik-201 and Rik-203 in mouse ES cells, Zhang et. al. proved their importance in neural differentiation. Repression of lncRNAs Rik201 and Rik-203 contributes to inhibition of neural differentiation by modulating the expression of SOX6 (Zhang et. al., 2019 b). A separate study identifies lncRNA Sox2OT as a promoting factor for cortical neural progenitors by repressing the expression of pluripotent gene Sox2 via physical interaction with multifunctional transcriptional regulator YY1 (Knauss et. al., 2018). Another example of regulation of Sox 2 expression by a lncRNA which alters the neural stem fate is by lncRNA Rmst which physically interacts with SOX2 to alter the outcome (Ng et. al., 2013).

LncRNA Mrhl (meiotic recombination hotspot locus), a lncRNA that has been studied extensively by our group, is the focus of our present study (Nishant et. al., 2004; Ganesan \& 
Rao, 2008; Arun et. al., 2012; Akhade et. al., 2014; 2016; 2017; Pal et. al., 2021). Mrhl is an intronic and single exonic lncRNA with a length of $2.4 \mathrm{~kb}$. This nuclear restricted lncRNA is transcribed from the $15^{\text {th }}$ intron of $P h k b$ gene in mouse and shows syntenic conservation in humans (Ganesan \& Rao, 2008; Fatima et. al., 2019; Choudhury et. al., 2020, Preprint). LncRNA Mrhl is found to be a negative regulator of WNT signaling via its interaction with p68/DDX5 RNA helicase in mouse spermatogonial cells (Ganesan \& Rao, 2008; Arun et. al., 2012; Akhade et. al., 2016). LncRNA Mrhl has also been shown to regulate Sox8 at chromatin level signifying its role in meiotic commitment of mouse spermatogonial progenitor cells (Akhade et. al., 2014). Our latest finding from transcriptomics and genome-wide occupancy studies of Mrhl in mouse ES cells has revealed its role as a chromatin regulator of cellular differentiation and development genes (Pal et. al., 2021).

Taking clue from our recent study (Pal et. al., 2021) where a large number of genes related to neural development and differentiation were dysregulated upon Mrhl downregulation, we explored the dynamic expression pattern of lncRNA Mrhl and its transcriptional regulation during mouse neuronal lineage development in the present study. We have shown that Mrhl is predominantly expressed in the neuronal progenitor populations in the ventricularsubventricular zones of developing mouse embryonic brains. We have adopted an in vitro model system of retinoic acid mediated derivation of radial-glia like neuronal progenitor cells (NPCs) from mouse ES cells. Mrhl shows up regulation of expression in these NPCs. Levels of lncRNA Mrhl is significantly down regulated in postnatal brains and in maturing neurons suggesting its significance in embryonic neuronal lineage development. We have also identified PAX6, a master transcription factor in NPCs, to be a regulator of Mrhl transcription. Further exploration of mechanism reveals that PAX6 can do so by physically binding to the promoter of Mrhl at multiple sites of action. A major site of action for PAX6 on Mrhl promoter is situated $2.9 \mathrm{~kb}$ upstream of the TSS where it binds directly and regulates Mrhl in NPCs. Three other minor sites are present at 1.27kb, 672bp and 622bp upstream of the TSS of Mrhl wherein regulation is proposed to be by PAX6 and/or its isoform PAX6(5A) and potentially in conjunction with other co-factors. NFAT4, which is another important transcription factor in neuronal development, was also found to be enriched at the promoter region of Mrhl at two sites in the proximal promoter, 437bp and 143bp upstream of the TSS. ChIP studies verifies interactions of PAX6 and NFAT4 with each other leading to the assumption that PAX6 might regulate Mrhl in coordination with NFAT4 in NPCs. This study thus reveals regulated 
expression of lncRNA Mrhl by multiple and specific transcription factors during neuronal lineage development.

\section{Results}

\section{Mrhl is predominantly expressed in embryonic stages of the mouse brain and in neuronal} progenitor population

Our recent study on the transcriptome analysis of mouse ES cells following down regulation of Mrhl lncRNA showed an over representation of neuronal lineage-specific genes and networks to be dysregulated (Pal et. al., 2021). Based on this observation we initiated this study towards addressing the role of Mrhl in neuronal lineage specification. To begin with, we analyzed its expression level in the mouse brain tissues of both embryonic and postnatal mice. We performed qRT-PCR on brains from embryonic stages E10.5-E18.5 and postnatal stages P0-P40 and observed that Mrhl expression is predominantly abundant in stages E12.5-E18.5 (Fig. 1A). Furthermore, Mrhl showed abrupt decrease in expression level from postnatal stage P0 onwards. At around E8 of brain development, neuroepithelial cells of the neural tube give rise to radial glia cells (RGCs), the future NPCs of the brain. RGCs undergo rapid proliferation and specification into basal progenitors which in turn give rise to neurons, with a peak of neurogenesis at E14 (Yao \& Jin, 2014). Since we observed the first peak of Mrhl expression at E14.5 in our studies, we focused to understand its role at this stage. We isolated brain tissue from E14.5 embryos and divided them into fore-, mid- and hind-brain regions based on their gross anatomy. We confirmed the purity of the three regions obtained based on forebrain specific marker FoxG1, midbrain specific marker En1 and hindbrain specific marker Gbx2 (Kirkeby et. al., 2012; Su et. al., 2018). Pax6 was used a control marker owing to its defined expression pattern across the three regions of the brain. We observed that Mrhl is expressed ubiquitously across all the three regions of the mouse brain at E14.5 (Fig. 1B). Whilst Mrhl may have specific roles to play across all regions of the developing brain, we concentrated on the forebrain development. To further narrow down into the specific cell types in which Mrhl might be involved in the forebrain, we performed RNA FISH for Mrhl along with IF for PAX6 as the marker, on whole forebrain sections at E14.5. We found that Mrhl is expressed specifically in the ventricular/subventricular zone of the brain at this stage (Fig. 1C). This was further confirmed by analyzing publicly available ChIP-Seq datasets [GSE93009] for RNA Pol II, RNA Pol II-Ser5p (initiation polymerase), transcription activation mark, H3K4me3 and 
transcription repression mark, $\mathrm{H} 3 \mathrm{~K} 27 \mathrm{me} 3$, on the proximal $1 \mathrm{~Kb}$ promoter of Mrhl in Nestin+ NPCs isolated from E15.5 cortices (Liu et. al., 2017). The analysis showed us distinct enrichments for RNA Pol II, initiating RNA Pol II and H3K4me3 near the TSS for Mrhl (Fig. 1D). Thus, we concluded that Mrhl is predominantly expressed in the neuronal progenitor population of the developing embryonic mouse brain.

\section{Mrhl expression pattern in mouse brain is recapitulated in an in-vitro differentiation model}

We adopted the well-established RA induced in vitro differentiation model system to further elucidate Mrhl as a molecular player in NPCs. We generated EBs from mouse ES cells and treated them with retinoic acid (RA). This method has been shown to generate PAX6+ RGClike NPCs that possess the capability to generate neurons in vivo, as shown by the study of Bibel et. al. and Plachta et. al. (Bibel et. al., 2007; Plachta et. al., 2004). We observed that Mrhl is up regulated in expression in RA treated EBs as compared to vehicle treated EBs (Fig. 2A). An analysis for various NPC markers such as Pax6 and Nestin as well as neuronal markers such Tuj1 and Ascl1 confirmed our in vitro neuronal lineage differentiation system (Fig. S1A, B). We next differentiated these in vitro derived neuronal progenitors into neurons and observed that Mrhl expression is abruptly down regulated from 12 hours post neuron formation (Fig. 2B). We further confirmed our observations through RNA FISH for Mrhl and IF for NESTIN on cryosections of RA versus vehicle treated EBs. RA treated EB sections showed noticeable expression for Mrhl as compared to vehicle treated sections (Fig. 2C). Similarly, Mrhl showed significant reduction in expression from early neuron stage at 12 hours (Fig. 2D, S1C). We also performed ChIP-qPCR on RA treated EBs and neurons at 24 hours of differentiation for $\mathrm{H} 3 \mathrm{~K} 4 \mathrm{me} 3$, an active transcription mark, and the results indicated a decreased association of this histone mark at the Mrhl promoter in maturing neurons (Fig. 2E). Our observations thus confirm that Mrhl is preferentially expressed in NPCs.

\section{A master transcription factor PAX6 was identified as a regulator of Mrhl in NPCs}

Next, we were interested in understanding how the transcriptional activity of Mrhl is regulated in neuronal progenitors. LncRNAs act in close coordination with TFs to not only regulate target genes but also be regulated themselves. LncRNA Rmst, also known as Ncrms, has been shown to be positively regulated by PAX2, a TF involved in midbrain and cerebellum development (Bouchard et. al., 2005) whereas it is negatively regulated by REST, during neurogenesis (Ng et. al., 2013), emphasizing the context-dependent transcriptional regulation of IncRNAs by 
major TFs. STAT3 has been shown to up regulate the expression of lncRNA Hoxd-As1 at the transcription level, contributing to invasion and metastasis in hepatocellular carcinoma (Wang et. al., 2017). During male germ cell meiotic commitment, Mrhl is repressed in transcription by the WNT signaling pathway effector, TCF4/ $\beta$-CATENIN complex along with the corepressor CTBP1, via interaction at its promoter (Akhade et. al., 2016).

We used a combination of GPMiner (Lee et. al., 2012) and JASPAR (Mathelier et. al., 2014) programs to gain insights into the probable transcriptional regulators of Mrhl in neuronal progenitors. An analysis for $3 \mathrm{~kb}$ upstream of TSS region for Mrhl revealed predicted binding sites for diverse lineage specific TFs (Fig. S2A). With respect to the neuronal lineage, TCF4 (172bp), PAX6 (2904bp, 1276bp, 672bp and 622bp), RBPJ-K (484bp), NFAT (437bp and 143bp) and MEIS1 (477bp) were of noticeable importance (Fig. S2A and Supplementary File 1). Initially, we focused on TCF4, an effector of the WNT pathway owing to our earlier studies on WNT mediated regulation of Mrhl in B-type spermatogonial progenitors. Additionally, the WNT pathway has been shown to be involved in context-dependent roles in neural development (Chenn \& Walsh, 2002; Machon et. al., 2003; Woodhead et. al., 2006). Towards this end, we performed IF for $\beta$-CATENIN on RA treated versus vehicle treated EBs as well as during neuronal differentiation over a time period of 2h-24h (Fig. S2B). We observed no translocation of $\beta$-CATENIN from membrane to the nucleus, a hallmark of non-activation of the WNT pathway. Hence, we ruled out TCF4 as a potential transcriptional regulator for Mrhl in RA derived NPCs. Our studies also suggest that WNT signaling may not have a role to play in RA derived NPCs. We additionally probed into RBPJ-K, an effector of the NOTCH pathway, since NOTCH signaling has been extensively implicated in the proliferation and maintenance of radial glia progenitors in the brain (Gaiano et. al., 2000; Mizutani et. al., 2007; Imayoshi et. al., 2010; Sakamoto et. al., 2003). We performed IF for NICD in vehicle treated versus RA treated EBs and observed translocation of NICD to the nucleus of RA derived NPCs (Fig. S2C), indicating activation of the NOTCH pathway. However, subjecting RA treated EBs to the NOTCH pathway inhibitor DAPT, showed a reduction in expression for the known target Hes5 but not for Mrhl (Fig. S2D), thereby ruling out RBPJ-K as the potential regulator for Mrhl. We also did not see changes in expression levels for other neuronal markers such as Pax6 and Tuj1, suggesting in RA derived NPCs, NOTCH signaling maybe acting through other pathways altogether to regulate progenitor physiology. We then focused on PAX6 whose role in neural development w.r.t NPCs and neurogenesis has been well established (Sansom et. al., 2009; Thakurela et. al., 2016). We collected ChIP-Seq datasets available for PAX6 in E12.5 
mouse embryonic forebrain [GSE 66961] (Sun et. al., 2015) and combined them with a FIMO analysis for PAX6 motifs (Xie \& Cvek1, 2011; Xie et. al., 2013). We narrowed down four binding sites on the promoter of Mrhl as candidates for PAX6 mediated regulation (Fig. 3A, sites 1, 2, 3 and 4). The FIMO analysis further revealed the presence of motifs 1-1 and 2-1 in site 1, motifs 1-3 and 3-3 in site 2 and motif $4-1$ in sites 3 and 4 (Fig. 3B-D, Table 1, Supplementary File 1). ChIP-qPCR for PAX6 corresponding to sites 1 to 4 on Mrhl promoter showed that PAX6 occupies all sites in E14.5 brains and sites 1, 3 and 4 in RA treated EBs (Fig. 3E-F, S3A). We concluded here that PAX6 is potentially regulating Mrhl at the transcriptional level in NPCs.

\section{PAX6 physically binds to the distal promoter and regulates Mrhl in NPCs}

We next performed an in-depth analysis involving EMSA, luciferase and knockdown assays to understand the regulation of Mrhl by PAX6 at these four sites. We expressed and purified fulllength PAX6 and its isoform PAX6(5A) (Fig. S3B) for our EMSA experiments (Table 1). We observed that PAX6 binds directly to site 1 on Mrhl promoter strongly, to site 2 weakly and does not bind to sites 3 and 4 (Fig. 4A). Elaborate studies by Xie and Cvekl (Xie \& Cvekl, 2011) have shown that PAX6 binds to nine novel motifs, only one of which corresponds to the consensus. Furthermore, PAX6 and PAX6(5A) bind to these motifs with varying affinities depending on the biological context. Since, we observed occupancy of PAX6 in our ChIP results on sites 2, 3 and 4 and since it has already been demonstrated that motif 1-3 in site 2 and motif $4-1$ in sites 3 and 4 are bound by PAX6(5A) with moderately high affinity (Xie \& Cvekl, 2011), we hypothesized, sites 2, 3 and 4 might be bound by the isoform PAX6(5A). PAX6(5A) differs from PAX6 in that it has a 14 amino acid insertion in the PAI domain, thereby its differential binding to the various motifs. Furthermore, studies have shown that the ratio of PAX6:PAX6(5A) shifts from 8:1 to 3:1 from stages E12.5 to E14.5 of development (Pinson et. al., 2005). However, our EMSA studies showed no binding for PAX6(5A) to any of these sites (Fig. S3C). We then carried out luciferase assays in P19EC cells which lack expression of endogenous PAX6 using various constructs of Mrhl promoter harboring one or the other sites as shown in Fig. 4B-D in the presence of ectopically expressed PAX6 or PAX6(5A). Sites 3 and 4 did not elicit any luciferase activity. However, both sites 2 and 1 displayed luciferase activity in the presence of both the isoforms. Furthermore, luciferase assays in the presence of both the isoforms revealed highest activity at a ratio of 4:1 for PAX6:PAX6(5A) for the Mrhl promoter (Fig. 4E). Finally, we generated doxycycline inducible PAX6 knockdown mouse ES cell lines and induced the knockdown of PAX6 at day 
5 of RA mediated differentiation of EBs and scored for Mrhl expression. We observed a reduction in Mrhl expression concomitant with reduction of PAX6 expression (Fig. 4F). From these studies we infer that PAX6 transcriptionally regulates Mrhl in neuronal progenitors through direct physical binding at site 1 on the distal promoter of Mrhl. Site 2 may also be a point of regulation by PAX6/PAX6(5A) as is evidenced by our ChIP and luciferase assays probably in conjunction with other TFs/cofactors. It has been shown that other TFs such as SOX2 act in conjunction with PAX6 to regulate enhancers of target genes in lens (Kamachi et. al., 2001). Sites 3 and 4 showed enrichment for PAX6 in our ChIP assays but no binding or activity in our EMSA and luciferase assays, respectively, suggesting regulation via these two sites might be highly context dependent.

\section{Regulation of Mrhl by NFAT4 in NPCs at the proximal promoter}

The experiments described above clearly demonstrate that PAX6 regulates Mrhl expression in NPCs, majorly through the upstream distal site 1 at $2.9 \mathrm{~kb}$ in the promoter of Mrhl. We argued that there must be other TFs that act to regulate Mrhl via its proximal promoter and they may act in conjunction with PAX6. From our earlier analysis of the $3 \mathrm{~kb}$ upstream of TSS region for Mrhl, we observed that NFAT and MEIS1 have potential binding sites in the proximal promoter of Mrhl. MEIS1 has been implicated in innervation in the neural crest (Bouilloux et. al., 2016), during RA mediated neural differentiation of mouse P19EC cells (Yamada et. al., 2013) and in granule cells during development of the cerebellum (Owa et. al., 2018). NFAT has been implicated in being involved in various aspects of neural development such as axon growth, neuronal survival and synapse communication (Vihma et. al., 2016; Wild et. al., 2019). NFAT showed two possible binding sites at 143bp (BS 1) and 437bp (BS 2) upstream from Mrhl TSS, while MEIS1 binding site was found at 477bp upstream. Since NFAT has four isoforms, all of which are involved in neural pathways, we first established which isoform of NFAT could be regulating Mrhl in NPCs through PCR studies. We observed that only NFAT4 is expressed in both E14.5 embryonic brain as well as in EBs (Figure 5A and S4A). We further observed that NFAT4 exhibits the highest expression amongst all isoforms in embryonic brains (expression was compared w.r.t P4 brain in each case, Figure S4B). We next performed ChIP-PCR to verify the enrichment of both NFAT4 and MEIS1 at the promoter site of Mrhl. Our result show highly significant enrichment of NFAT4 at both the predicted binding sites (Figure 5B). Although MEIS1 also showed significant enrichment at the Mrhl promoter, the enrichment was $\sim$ 4-fold less as compared to NFAT4. Therefore, we focused on NFAT4 herewith and tried to determine if it interacts with PAX6 for a possible co-regulation of Mrhl. Co-ChIP western blots 
clearly demonstrated enrichment of NFAT4 during PAX6-IP (Figure 5C) and vice-versa (Figure 5D). Findings from these results lead us to the conclusion that PAX6 regulates Mrhl at the distal promoter whereas NFAT4 acts to possibly regulate Mrhl at the proximal promoter in NPCs. There is a further possibility that PAX6 and NFAT4 act to co-regulate lncRNA Mrhl in NPCs towards regulating cell fate decisions (Figure 5E-F).

\section{Discussion}

The role of lncRNAs in development, differentiation, regulation of lineage specification. and maintenance of pluripotency is well established now with numerous examples reported in the literature. Using high throughput technologies, a large number of lncRNAs have been found to be expressed during neural development and in the brain (Li et. al., 2019; Zhao et. al., 2020; Roberts et. al., 2014; Briggs et. al., 2015; Hart \& Goff, 2016; Mercer et. al., 2008; Derrien et. al., 2012; Kadakkuzha et. al., 2015; Liau et. al., 2021; Lv et. al., 2013; Antoniou et. al., 2014; Dinger et. al., 2008). Owing to their specificity, tight spatial and temporal regulation of expression and functions, lncRNAs have been shown to be more potent indicators of cell types in brain than their protein-coding counterpart, the mRNAs. The roles of many lncRNAs such as Dali, Paupar, Evf2, Rmst, Pnky, to name a few, in regulating neural progenitor proliferation and/or differentiation and gene regulation has already been reported, with new additions every year (Ng et. al., 2013; Chalei et. al., 2014; Xu et. al., 2021; Alammari, 2019; Feng et. al., 2006; Stamou et. al., 2020; Andersen, 2019; Ramos et. al., 2015). A recent study demonstrates that lncRNA SenZfp536 suppresses proliferation of cortical NPCs by cis-regulating the proteincoding gene Zfp536 via mechanism of chromosomal looping (Tian et. al., 2021). While in another study, lncRNA Neat1 was found to induce neuron specific differentiation and to promote migration ability in spinal cord neural stem cells of mice by regulating $\mathrm{WNT} / \beta$-catenin signaling. In this study, the authors also gave evidence of regulation of lncRNA Neat1 expression by miR-124 (Cui et. al., 2019). Study by Lei et. al. shows expression level of LncRNA Rik-203 to be increased during neural differentiation. Their data suggest that it facilitates neural differentiation by inhibiting miR-101a-3p's ability to reduce GSK-3 $\beta$ levels (Zhang et. al., 2019 c).

Role of lncRNA Mrhl in development and differentiation has already been established in our previous studies (Arun et. al., 2012; Akhade et. al., 2014; 2016; Pal et. al., 2021). Nuclear restricted Mrhl RNA has a definitive role in differentiation of B type spermatogonial cells into 
meiotic spermatocytes. Mrhl does so by negatively regulating WNT-signaling pathway, which is activated in differentiated meiotic spermatocytes, in association with p68/DDX5 helicase (Arun et. al., 2012). On the other hand, in the context of mESCs, shRNA mediated depletion and subsequent transcriptome analysis have revealed genes related to developmental processes, lineage-specific transcription factors and key networks to be dysregulated along with aberrance in specification of early lineages during differentiation of mESCs (Pal et. al., 2021). Interestingly, gene ontology analysis after Mrhl knockdown revealed 'development process' category to be enriched as the most important one with maximum number of dysregulated genes, most of them being related to the neuronal lineage. Furthermore, nervous system also emerged as one of the perturbed clusters in gene co-expression analysis. Genome-wide chromatin occupancy studies further predicted important neuronal TFs such as POU3F2 and FOXP2 to be directly regulated at the chromatin level by Mrhl RNA. Our present study validated further that Mrhl is a key molecular player in neuronal lineage development.

Neuronal differentiation is a highly complex process which requires intertwined action of various signaling pathways and transcription factors involved in regulating various aspects of neural stem cells/progenitor proliferation and neurogenesis. The peak of lncRNA Mrhl expression at E14.5 concurrent with the peak of neurogenesis in mouse brain development along with the abrupt inhibition of Mrhl expression from postnatal stage P0 onwards is intriguing. This is also observed in the RA induced neuronal differentiation model system. This observation indicates that Mrhl may have an important role to play in neuronal progenitor specification/maintenance processes during embryonic brain development. Similar observations were also reported by Lv et.al. (Lv et. al., 2013) where transcriptomics analysis revealed embryonic restricted expression for many lncRNAs. For example, they detected an intronic lncRNA (chr15:66,090,924-66,092,050) which is highly expressed in early embryonic stages and the expression is decreased to basal level from E17.5. As another example, they also identified lncRNA Zfhx2as with increasing expression in E13-E16 peaking at E17 while only basal expression in brain after birth. They concluded that embryonic restricted expression of lncRNAs have regulatory roles in the developing brain (Lv et. al., 2013). It would be most interesting to delineate the mechanism of this shutting off of Mrhl expression in the postnatal brain as well as in the maturing neurons in the RA model system.

The mechanisms regulating this developmental stage specific expression of lncRNAs is still not fully understood. However, studies have indicated that chromatin state, including the crosstalk between DNA methylation and histone modification might be one of the mechanisms 
(Lv et. al., 2013; Wu et. al., 2010; 2014). It has also been reported that miRNAs, specific DNA sequences as in case of lncRNA known as promoter-associated ncRNAs (pancRNAs), specific location of lncRNA with respect to protein coding genes, and sometimes the transcript itself are involved in modulating the expression of lncRNA in cell and stage specific manner (Cui et. al., 2019; Wu et. al., 2014; Engreitz et. al., 2016). LncRNAs also seem to be regulated by the same set of transcription factors that influence the expression of protein coding genes. A transcriptomic profile study on mouse retinal photo receptor cells, done at six developmental time points in mouse, reveals regulation of $\sim 20 \%$ of expressed lncRNAs is under control of the rod differentiation factor, neural retina leucine zipper (NRL), predicting their role in development and differentiation of rod cells (Zelinger et. al., 2017). Regulation of lncRNAs by various TFs in cancers has also been reported recently (Sun et. al., 2019; Huang et. al., 2017). As mentioned before, direct binding and transcriptional regulation of lncRNAs by key mouse ES cell transcription factors, OCT4 and NANOG, have been reported to modulate the pluripotency of ES cells (Mohamed et. al., 2010). In our efforts to identify key transcription factors that regulate the differential expression of Mrhl RNA during neuronal development, our bioinformatics analysis revealed the presence of PAX6 DNA binding sites in the upstream region of the Mrhl gene which were also occupied by the PAX6 protein at the chromatin level. PAX6 is an important pioneer transcription factor that has proven role in the regulation of neuronal development (Sansom et. al., 2009; Thakurela et. al., 2016). PAX6 is also a unique transcription factor in that it does not have a definite cognate DNA binding site but has a set of 10 overlapping DNA binding motifs which function in a very context dependent manner (Xie \& Cvekl, 2011). Our extensive analysis presented here has shown that among the 4 PAX6 occupied DNA binding sites, site 1 situated 2904bp upstream of Mrhl TSS, is of relevance for the direct regulation of Mrhl expression in NPCs. Since this PAX6 binding site is far upstream of the TSS, we argued that PAX6 might interact with one of the transcription factor that binds to the proximal promoter region. This assumption was also based on reports wherein it has been shown that PAX6 may not act in isolation but interacts with other transcription factors forming a ternary complex (Kamachi et. al., 2001) or with chromatin proteins to regulate promoters and enhancers (Sun et. al., 2016). Among the four transcription factors that have binding sites within the proximal promoter region of the Mrhl gene, we found that PAX6 interacts with NFAT4 as monitored by co-immunoprecipitation assays. It is interesting to note that NFAT4 is also neuronal lineage specific transcription factor (Vihma et. al., 2016; Wild et. al., 2019). Another major observation made in the present study is that WNT signaling is not involved in the regulation of Mrhl gene in RA derived NPCs which is in contrast to its role B- 
type spermatogonial cells. Thus, it is likely that Mrhl gene is regulated by different sets of transcription factors in a lineage specific manner.

The regulation of lncRNA Mrhl by PAX6/PAX6(5A) through multiple sites of action in NPCs, independently or in probable conjunction with co-factors presents forth a wonderful interplay of lncRNAs and proteins in coordinating cell-specific events. However, recognizing the complexity in lineage specification and interplay between several regulation factors, we also cannot rule out the fact that other TFs or cofactors may also be involved in this mechanism. For example, we found the presence of RARE (retinoic acid response elements) sites on the $3 \mathrm{~kb}$ upstream promoter region for Mrhl. In the context of the RA induced neuronal model system, this becomes worthy of exploration. Furthermore, it would be interesting to study if this Mrhl-PAX6-NFAT4 interaction dynamics is important for the maintenance of the NPC pool during embryonic brain development as well as probe into other factors that are involved in the aforementioned dynamics. It would be particularly interesting to delineate the chromatin based mechanisms behind regulation of Mrhl by these two TFs in NPCs.

Regulation of spatial and temporal expression of lncRNAs indeed adds to their functional role in context specific manner. Expression of lncRNA Mrhl itself is restricted to testis, liver, kidney \& spleen of adult mouse (Nishant et. al., 2004; Ganesan \& Rao, 2008). It's expression in mouse ES cells and spermatogonial progenitor cells signifies its role in development (Arun et. al., 2012; Akhade et. al., 2014; 2016; Pal et. al., 2021). The present study has shown that the expression of Mrhl is restricted to embryonic stages of brain and NPCs with minimal basal levels in maturing neurons and postnatal brain. At this juncture, an important question that needs to be addressed in the future is the biological relevance of differential expression of Mrhl RNA during neuronal development. The approach of transcriptome analysis in NPCs depleted of Mrhl should give valuable information about the gene targets of Mrhl RNA in NPCs. We would like to add here that the gene targets of Mrhl lncRNA are quite different in the mouse spermatogonial cells and ES cells (Akhade et. al., 2014; Pal et. al., 2021) highlighting that the gene targets will be cell type specific and context dependent. Thus, the present study has demonstrated an unexpected and a new role for lncRNA Mrhl in neuronal development. Future studies on the molecular and cellular functions of Mrhl lncRNA in neuronal development should add to the diversity of cellular functions exhibited by this lncRNA. 
Materials and Methods

447

\section{Cell lines, plasmids, reagents and oligos}

E14TG2a feeder independent mouse ES cell line was a kind gift from Prof. Tapas K. Kundu's lab (JNCASR, India). mouse ES cells were maintained on $0.2 \%$ gelatin (Himedia, TC041) coated dishes and grown in DMEM high glucose (Dulbecco's modified Eagles' medium), high glucose (Sigma, D1152), 15\% FBS (Gibco, 16000-044), 1X non-essential amino acids (Sigma, M7145), $0.1 \mathrm{mM} \quad \beta$-mercaptoethanol and 1X penicillin-streptomycin (Sigma, P4333) supplemented with ESGRO (Merck Millipore). P19EC line was a kind gift from Prof. Kumar Somasundaram's lab (IISc, India) and grown in in DMEM, 10\% FBS, $0.1 \mathrm{mM} \beta$ mercaptoethanol and 1X penicillinstreptomycin. HEK293T cell line (ATCC, USA) was maintained in DMEM, 10\%FBS and 1X penicillinstreptomycin.

PAX6 shRNA (in the SMART vector inducible lentiviral backbone) clone was obtained from Horizon Discovery, cloneID: V3IMMPGG_11530401. p3x-FLAG-CMV-10 (Sigma) was used for the generation of PAX6 and PAX6(5A) expression vectors. PAX6 and PAX6(5A) were amplified from cDNA of E14.5 mouse embryonic brains and cloned into the vector.

pGL4.10 (luc2) vector (Promega, E6651) was used for the generation of Mrhl promoter constructs for luciferase assays. $1.25 \mathrm{~kb}, 1.5 \mathrm{~kb}$ or $3.25 \mathrm{~kb}$ of the Mrhl promoter (250 bp were taken downstream of the transcription start site in each case) were amplified from genomic DNA and cloned into the vector.

All fine chemicals were obtained from Sigma (unless otherwise mentioned), gelatin was obtained from Himedia and FBS was obtained from Gibco (Performance Plus, US Origin).

Antibodies and oligo sequences have been listed in Supplementary File 2.

\section{Animal procedures}

473 CD-1 strain of mice (species: Mus musculus) were used for isolating embryonic and postnatal 474 brains at indicated stages. For embryonic brain isolation, female mice at age 6-8 weeks were 475 bred with males and were checked for plugs to confirm mating. Day of positive plug was considered as $0.5 \mathrm{dpc}$. All animal procedures were performed in accordance with the Institutional Animal Ethics Committee of JNCASR, India. 


\section{Transfection/transduction protocols}

480

481

482

483

484

485

486

487

488

489

490

491

492

493

494

495

496

497

498

499

500

501

502

503

504

505

506

507

508

509

510

Transfections for P19EC and HEK293T cells were performed using Lipofectamine 2000 (Thermo Fisher Scientific, 11668019) as per the manufacturer's protocol. Transduction of mESCs was performed as per the protocol of Pijnappel et. al. (Pijnappel et. al., 2013). Briefly, HEK293T cells were transfected with $5 \mu \mathrm{g}$ PAX6 shRNA plasmid, $2.5 \mu \mathrm{g}$ pSPAX2, $1.75 \mu \mathrm{g}$ pVSVG and $0.75 \mu \mathrm{g}$ pRev to generate the viral particles. The media containing viral particles was harvested 48 hours after transfection. A second round of viral particles was collected after an additional 24 hours. The viral supernatant was mixed with $8 \mu \mathrm{g} / \mathrm{ml}$ DEAE-dextran and 1000 units/ml ESGRO and added directly to the E14TG2a cells. Transduction was performed for 24 hours with the first round of viral particles and an additional 24 hours with the second round of viral particles. The transduced cells were then subjected to puromycin selection $(1.5 \mu \mathrm{g} / \mathrm{ml}$ puromycin) for a week.

\section{Neuronal differentiation of mESCs}

The protocol described by Bibel et. al. (Bibel et. al., 2007) was followed for retinoic acid mediated neuronal differentiation of mESCs. $4 \times 10^{6}$ cells were plated onto $100 \mathrm{~mm}$ bacteriological grade dishes (Greiner Bio-One, 633102) in differentiation medium containing DMEM, 10\% FBS, $0.1 \mathrm{mM} \beta$-mercaptoethanol and $1 \mathrm{X}$ penicillin-streptomycin and allowed to grow for 4 days. Retinoic acid [RA (Sigma, R2625)] or dimethyl sulfoxide [(DMSO), Sigma, D2650] was added to the EBs on the $4^{\text {th }}$ day at a final concentration of $5 \mu \mathrm{M}$ and allowed to grow for an additional 4 days. After a total of 8 days of differentiation (4-/4+ RA), the RA or vehicle DMSO treated EBs were harvested by gravity precipitation for cryosectioning. Alternatively, RA treated EBs were trypsinized to obtain NPCs with $0.05 \%$ freshly made trypsin for 3 minutes at $37^{\circ} \mathrm{C}$, dissociated and filtered through $40 \mu \mathrm{m}$ filters (Falcon, 352340). NPCs were collected by centrifugation at $1150 \mathrm{rpm}$ for 5 minutes.

For the generation of early and maturing neurons, plates or coverslips were coated with 100 $\mu \mathrm{g} / \mathrm{ml}$ poly-D-lysine (Merck Millipore, A-003-E) at $37^{\circ} \mathrm{C}$ overnight. Next day, plates were washed thoroughly three times with deionized sterile water and dried. The plates were then coated with laminin solution (Roche, 11243217001) for 2 hours at $37^{\circ} \mathrm{C}$ and kept ready for use. The cell pellet obtained above was resuspended in N2 medium containing DMEM/F12 (Sigma, D2906), 1X N2 (Thermo Fisher Scientific, 17502048) and 1X penicillin-streptomycin and plated at a density of 90,000 cells $/ \mathrm{cm}^{2}$. N2 medium was changed 2 hours after plating and then 
511

512

513

514

515

516

517

518

519

520

521

522

523

524

525

526

527

528

529

530

531

532

533

534

535

536

537

538

539

540

541

542

again after 24 hours. For further differentiation, medium was changed after an additional 24 hours to N2B27 medium containing DMEM/F12, 1X N2, 1X B27 (Thermo Fisher Scientific, 17504044) and $1 \mathrm{X}$ penicillin-streptomycin. Cells were harvested at different time points for appropriate analyses.

\section{PAX6 knockdown and Mrhl expression}

PAX6 shRNA clone was used to generate stable inducible mESC line. Protocol for retinoic acid mediated neuronal differentiation of mESCs as described above was followed. PAX6 knockdown was induced by addition of different concentrations of doxycycline $(0,2,3,3.5$ \& $4 \mu \mathrm{g} / \mathrm{ml}$ ) from day 3 onwards, every day. RA was added on $4^{\text {th }}$ day and EBs were harvested on day $5^{\text {th }}$. RNA was isolated from collected cells and qPCR was performed as described later, for expression level of PAX6 and Mrhl.

\section{NOTCH Inhibition studies}

EBs were treated with NOTCH inhibitor DAPT (N-[N-(3,5-Difluorophenacetyl)-L-alanyl]-Sphenylglycine t-butyl ester, Sigma D5942) at a concentration of $10 \mu \mathrm{M}$ on the $4^{\text {th }}$ day of differentiation along with RA. EBs were harvested on the $5^{\text {th }}$ day and processed directly for $\mathrm{qPCR}$ as described later.

\section{Preparation of NPC smears}

EBs were trypsinized and filtered as described earlier and cross-linked with $1 \%$ formaldehyde for 8 minutes at room temperature. Formaldehyde was quenched using $1 / 7^{\text {th }}$ volume of $1 \mathrm{M}$ glycine for 5 minutes at room temperature and cells were collected by centrifugation at 1500 rpm for 5 minutes at $4^{\circ} \mathrm{C}$. The cells were washed 3 times with ice cold $1 \mathrm{X}$ PBS and collected by centrifugation each time. A $10 \mu \mathrm{l}$ aliquot of the cell suspension in $1 \mathrm{X}$ PBS was taken on a slide, covered with a coverslip and dipped in liquid $\mathrm{N}_{2}$ to fix the cells on the slide (aliquot volume can be determined empirically to obtain desired cell density per aliquot). The cover slip was removed immediately thereafter with the help of scalpel blade. The slides were hydrated in 1X PBS for 3-5 minutes and dehydrated in graded ethanol from 50\%, 75\%, 95\% to $100 \%$. The slides can be stored in $100 \%$ ethanol at this point. Before proceeding for RNA FISH or IF, slides were rehydrated in the reverse order of ethanol series with a final rehydration step in $1 \mathrm{X}$ PBS. 
RNA FISH followed by IF on EBs, NPCs or brain tissues was performed as per the protocol of de Planell-Saguer et. al. (de Planell-Saguer et. al., 2010). The probes used for RNA FISH were Cy5 labelled locked nucleic acid probes procured from Exiqon (reported in Arun et. al.) (Arun et. al., 2012).

547 Fixation and permeabilization: Cells were either grown on coverslips or cell smears were prepared as described above. EBs or brain tissues were fixed in 4\% paraformaldehyde for 7-8 hours at $4^{\circ} \mathrm{C}$ followed by equilibration in $20 \%$ sucrose solution overnight and embedded in tissue freezing medium (Leica, 14020108926). The embedded tissues were then cryo-sectioned and collected on Superfrost slides (Fisher Scientific, 12-550-15). For cells, a brief wash was given with 1X PBS (phosphate buffered saline, $\mathrm{pH}$ 7.4) followed by fixation with $2 \%$ formaldehyde for 10 minutes at room temperature. The cells were then washed with $1 \mathrm{X}$ PBS three times for 1 minute each and permeabilization buffer (1X PBS, 0.5\% Triton X-100) was added for 5 minutes and incubated at $4^{\circ} \mathrm{C}$. The permeabilization buffer was removed and cells were washed briefly with $1 \mathrm{X}$ PBS for three times at room temperature. For tissue sections, antigen retrieval was performed by boiling the sections in $0.01 \mathrm{M}$ citrate buffer $(\mathrm{pH} 6)$ for 10 minutes. The sections were allowed to cool, washed in distilled water three times for 5 minutes each and then in $1 \mathrm{X}$ PBS for 5 minutes, each time with gentle shaking.

Hybridization: The samples were then blocked in prehybridization buffer [3\% BSA, 4X SSC (saline sodium citrate, $\mathrm{pH} 7$ )] for 40 minutes at $50^{\circ} \mathrm{C}$. Hybridization (Mrhl probes tagged with Cy5, final concentration $95 \mathrm{nM}$ ) was performed with prewarmed hybridization buffer (10\% dextran sulphate in $4 \mathrm{X} \mathrm{SSC}$ ) for 1 hour at $50^{\circ} \mathrm{C}$. After hybridization, slides were washed four times for 6 minutes each with wash buffer I (4X SSC, $0.1 \%$ Tween-20) at $50^{\circ} \mathrm{C}$ followed by two washes with wash buffer II (2X SSC) for 6 minutes each at $50^{\circ} \mathrm{C}$. The samples were then washed with wash buffer III (1X SSC) once for 5 minutes at $50^{\circ} \mathrm{C}$ followed by one wash with $1 \mathrm{X}$ PBS at room temperature. For tissue sections, all washes were performed as mentioned above with a time of 4 minutes for buffers I-III. The samples were then processed for IF.

IF: Samples were blocked with IF Blocking buffer (4\% BSA, 1X PBS) for 1 hour at $4^{\circ} \mathrm{C}$. Primary antibody solution (2\% BSA, 1X PBS) was prepared containing the appropriate dilution of desired primary antibody and the samples were incubated in it for 12 hours at $4^{\circ} \mathrm{C}$. Next day, the samples were washed with IF wash buffer (0.2\% BSA, 1X PBS) three times for 5 minutes each with gentle shaking. The samples were incubated in secondary antibody for 45 minutes at room temperature and washed with $1 \mathrm{X}$ PBS three times for 10 minutes each with gentle 
575

576

577

578

579

580

581

582

583

584

585

586

587

588

589

590

591

592

593

594

595

596

597

598

599

600

601

602

603

604

605

606

shaking. The samples were finally mounted in mounting medium containing glycerol and DAPI.

\section{Chromatin IP (ChIP)}

ChIP was performed according to Cotney and Noonan's protocol (Cotney \& Noonan, 2015). Protein A or protein G Dynabeads (Thermo Fisher Scientific, 10001D, 10003D) was used for rabbit or mouse antibodies respectively. For co-ChIP, same protocol was followed and whole sample after IP was processed for western blotting.

Preparation of antibody beads: $25 \mu \mathrm{l}$ dynabeads were used for each ChIP reaction. The beads were first washed with $1 \mathrm{ml}$ of bead binding buffer (1X PBS, 0.2\% Tween-20) and resuspended in $200 \mu \mathrm{l}$ of the buffer per reaction. H3K4me3 (2 $\mu \mathrm{g})$ or Pax6 (4 $\mu \mathrm{g})$ antibodies or their isotype controls were added to the beads in separate tubes and incubated for $\sim 16$ hours at $4^{\circ} \mathrm{C}$ on an end-to-end rotor at $10 \mathrm{rpm}$. The next day, beads were washed with $1 \mathrm{ml}$ of bead binding buffer followed by $1 \mathrm{ml}$ of dilution buffer (0.01\% SDS, $1.1 \%$ Triton X-100, $1.2 \mathrm{mM}$ EDTA, $16.7 \mathrm{mM}$ Tris- $\mathrm{HCl} \mathrm{pH} 8.1,167 \mathrm{mM} \mathrm{NaCl}$ ). The beads were then resuspended in $25 \mu \mathrm{l}$ dilution buffer per ChIP reaction and stored at $4^{\circ} \mathrm{C}$ for further use.

Chromatin extraction and quantification: Brain tissues from E14.5 dpc embryos or EBs were harvested in serum-free DMEM. Brain samples were minced with a scalpel blade and pipetted a few times whereas EBs were trypsinized and filtered as described earlier. The samples were then subjected to cross-linking using 1\% formaldehyde (Sigma, F8775) for 10 minutes at room temperature following which samples were quenched with glycine at a final concentration of $0.125 \mathrm{M}$ for 10 minutes at room temperature. The samples were then centrifuged at 2,000 g for 10 minutes at $4^{\circ} \mathrm{C}$ and washed twice with $1 \mathrm{X}$ ice-cold PBS. Finally, the pellets were either flash frozen in liquid $\mathrm{N}_{2}$ and stored in $-80^{\circ} \mathrm{C}$ or processed for chromatin extraction.

The cross-linked pellet was resuspended in six volumes of ice-cold cell lysis buffer $(50 \mathrm{mM}$ Tris-HCl pH 8.0, 140 mM NaCl, 1mM EDTA, 10\% glycerol, 0.5\% NP-40, 0.25\% Triton X100) supplemented with $1 \mathrm{X}$ mammalian protease inhibitor cocktail and incubated on ice for 20 minutes. For brain samples, the pellets were homogenized once after addition of lysis buffer with 30-40 strokes (BioSpec tissue tearor, 985370) and once after the incubation period was over. The nuclei were then harvested by centrifugation at $2,000 \mathrm{~g}$ for 5 minutes at $4^{\circ} \mathrm{C}$. The supernatant was removed, the nuclei were resuspended in five volumes of ice-cold nuclear lysis buffer (10 mM Tris-HCl pH 8.0, 1 mM EDTA, 0.5 mM EGTA, 0.5\% SDS) supplemented with 
607

608

609

610

611

612

613

614

615

616

617

618

619

620

621

622

623

624

625

626

627

628

629

630

631

632

633

634

635

636

1X mammalian protease inhibitor cocktail and incubated on ice for 20 minutes. The samples were then sonicated in Bioruptor (Diagenode, UCD-200) for 35 cycles (at pulses of 30sec on and $30 \mathrm{sec}$ off) and centrifuged at $16,000 \mathrm{~g}$ for 10 minutes at $4^{\circ} \mathrm{C}$ to remove insoluble material. The centrifuged samples were then transferred to fresh tubes, aliquoted as per requirement, flash frozen in liquid $\mathrm{N}_{2}$ and stored in $-80^{\circ} \mathrm{C}$.

For monitoring sonication efficiency and DNA quantification, $10 \mu \mathrm{l}$ aliquots was kept aside, diluted in $10 \mu \mathrm{l}$ of TE buffer and treated with $10 \mu \mathrm{g}$ of RNaseA (Sigma, R6513) for 30 minutes at $37^{\circ} \mathrm{C}$ followed by $20 \mu \mathrm{g}$ of proteinase K (Thermo Fisher Scientific, EO0491) for 1 hour at $55^{\circ} \mathrm{C}$. The aliquots were then subjected to reverse cross-linking for 5 minutes at $95^{\circ} \mathrm{C}$, allowed to cool to room temperature slowly and analyzed on $1 \%$ agarose gel for sonication efficiency or subjected to DNA isolation by phenol-chloroform method for quantification.

Immunoprecipitation: Approximately 10-25 $\mu \mathrm{g}$ of chromatin was diluted with dilution buffer supplemented with $1 \mathrm{X}$ mammalian protease inhibitor cocktail to reduce the SDS concentration to $<0.1 \%$ and achieve a final volume of $450 \mu \mathrm{l} .5 \%$ of the dilution was stored as input at $4^{\circ} \mathrm{C}$. $25 \mu \mathrm{l}$ of antibody or isotype control beads were added to the chromatin dilution and incubated for $12-16$ hours at $4^{\circ} \mathrm{C}$. Next day, the beads were washed with $1 \mathrm{ml}$ wash buffer (100 mM Tris-HCl pH 8.0, $500 \mathrm{mM} \mathrm{LiCl,} \mathrm{1 \%} \mathrm{NP-40,} \mathrm{1 \%} \mathrm{deoxycholic} \mathrm{acid)} \mathrm{supplemented}$ with $1 \mathrm{X}$ mammalian protease inhibitor cocktail for 5 times at room temperature. The beads were given a final wash with $1 \mathrm{ml}$ of TE buffer and resuspended in $85 \mu \mathrm{l}$ of elution buffer (50 $\mathrm{mM}$ Tris-HCl pH 8.0, $10 \mathrm{mM}$ EDTA, 1\% SDS). Elution was performed twice for 10 minutes each at $65^{\circ} \mathrm{C}$ under constant agitation in a thermo mixer. All ChIP and input samples (volume made upto $170 \mu \mathrm{l}$ with dilution buffer for input samples) were subjected to reverse crosslinking for 12 hours at $65^{\circ} \mathrm{C}$.

Chromatin purification and analysis: Next day, all samples were treated with $10 \mu \mathrm{g}$ of RNAse A for 1 hour at $37^{\circ} \mathrm{C}$ followed by $200 \mu \mathrm{g}$ proteinase $\mathrm{K}$ for 2 hours at $55^{\circ} \mathrm{C}$ and DNA was extracted by the phenol-chloroform method. The DNA was precipitated with $1 / 10^{\text {th }}$ volume $3 \mathrm{M}$ sodium acetate (ph 5.2), 3 volumes of $100 \%$ ethanol and glycogen at a final concentration of $0.5 \mu \mathrm{g} / \mu \mathrm{l}$ overnight at $-20^{\circ} \mathrm{C}$. Next day, DNA was pelleted, washed with $75 \%$ ethanol, dried, dissolved in sterile deionized water and subjected to qRT-PCR analysis. 
637

638

639

640

641

642

643

644

645

646

647

648

649

650

651

652

653

654

655

656

657

658

659

660

661

662

663

664

665

666

667

\section{Purification of PAX6 and PAX6(5A) proteins}

p3X-FLAG-CMV-10-Pax6 and -Pax6(5a) constructs were transfected into HEK293T cells. 24 $\mathrm{h}$ after transfection, cells were lysed in five volumes of FLAG lysis buffer (50 mM Tris-HCl $\mathrm{pH}$ 7.4, $150 \mathrm{mM} \mathrm{NaCl}, 1 \mathrm{mM}$ EDTA, $1 \%$ Triton X-100) supplemented with $1 \mathrm{X}$ mammalian protease inhibitor cocktail. To $500 \mu \mathrm{l}$ of supernatant containing proteins, $30 \mu \mathrm{l} \mathrm{M} 2$ agarose beads (Sigma, A220) were added and incubated for $3 \mathrm{~h}$ at $4^{\circ} \mathrm{C}$. The beads were then washed in $1 \mathrm{ml}$ of FLAG wash buffer $(50 \mathrm{mM}$ Tris- $\mathrm{HCl} \mathrm{pH} 7.4,150 \mathrm{mM} \mathrm{NaCl})$. The FLAG tagged proteins were then eluted in the FLAG wash buffer containing a final concentration of 500 ng/ $\mu$ l of FLAG peptide (Sigma, F4799).

\section{Electrophoretic Mobility Shift Assay (EMSA)}

End labelling of probe and purification: Oligos were designed such that they harboured the PAX6/PAX6(5A) motifs on Mrhl promoter. All forward oligos were subjected to end labelling with $\mathrm{r}$-32P-ATP in polynucleotide kinase reaction buffer [PNK buffer in a final concentration of 1X, 40pmol oligo, 20 units PNK enzyme (NEB, M0201S), $30 \mu \mathrm{Ci} \gamma$-32PATP, volume made upto $50 \mu \mathrm{l}$ with nuclease free water] for 30 minutes at $37^{\circ} \mathrm{C}$. The enzyme was heat inactivated for 20 minutes at $65^{\circ} \mathrm{C}$. The oligos were purified by the phenol-chloroform method and precipitated in $1 / 10^{\text {th }}$ volume of $3 \mathrm{M}$ sodium acetate, ph $5.2,3$ volumes of $100 \%$ ethanol and $10 \mu \mathrm{g}$ yeast tRNA for 1 hour at $-80^{\circ} \mathrm{C}$. The oligos were pelleted by centrifugation at 12,800 rpm for 10 minutes, washed in $75 \%$ ethanol and dried. They were then dissolved in $1 \mathrm{X}$ annealing buffer (10 mM Tris- $\mathrm{HCl}$ ph 8.0, $20 \mathrm{mM} \mathrm{NaCl}$ ). To each of the forward oligos, three times excess of the reverse oligos were added, heated for 10 minutes at $95^{\circ} \mathrm{C}$ and allowed to cool slowly over several hours to overnight at room temperature. The annealed probes were purified using sephadex C-50 columns. Glass wool was packed near the tip of a $1 \mathrm{ml}$ syringe till $0.1 \mathrm{ml}$ and the syringe was packed with C-50 beads slurry till $1 \mathrm{ml}$ with centrifugation at $1800 \mathrm{rpm}$ for 3 minutes at $4^{\circ} \mathrm{C}$. A final centrifugation was performed for the packed beads to remove all water before loading the annealed probes onto the column. The annealed probes were collected again by centrifugation and their activity was noted as counts per minute (cpm) in a scintillation counter. Unlabelled forward oligos were also annealed to their corresponding reverse oligos and purified in a similar manner for competition assay.

Binding reaction and electrophoresis: The purified proteins were allowed to bind to the oligos in a reaction mix containing 5X EMSA Buffer (60 mM Hepes-KOH ph 7.9, $300 \mathrm{mM}$ 
$\mathrm{KCl}, 15 \mathrm{mM} \mathrm{MgCl} 2,2.5 \mathrm{mM}$ DTT, 20\% w/v Ficoll 400, $1 \mathrm{mg} / \mathrm{ml}$ BSA, $1 \mathrm{X}$ mammalian protease inhibitor cocktail added just before use) to a final concentration of 1X, PAX6 or PAX6 (5A) purified proteins (100ng to 400ng in increasing concentrations), $400 \mathrm{ng} / \mu \mathrm{l} \mathrm{salmon}$ sperm DNA (Sigma, D9156) and $\gamma$-32P-ATP labelled double stranded oligo $(20,000 \mathrm{cpm})$. The volume was made upto $12.5 \mu \mathrm{l}$ with nuclease free water. The reaction was incubated for 40 minutes at $37^{\circ} \mathrm{C}$. For competition assay, 125X molar excess of unlabelled double stranded probe was used. After incubation, loading dye was added to the samples (containing bromophenol blue, xylene cyanol and without SDS) and the samples were run on a 5\% native gel (40\% acrylamide stock in 30:08 ratio of acrylamide to bis-acrylamide) prepared in $0.5 \mathrm{X}$ TBE (10X TBE stock: $1.8 \mathrm{M}$ tris base, $90 \mathrm{mM}$ boric acid, $2.5 \mathrm{mM}$ EDTA) at $150 \mathrm{~V}$ at $4^{\circ} \mathrm{C}$. The gel was then dried and exposed to Xray film for 24 hours.

\section{Luciferase and $\beta$-galactosidase Assay}

P19EC cells were transfected with $2 \mu \mathrm{g}$ of pGL4-Mrhl promoter constructs, $200 \mathrm{ng}$ of PAX6 or PAX6(5A) expression plasmids and $50 \mathrm{ng}$ of $\beta$-gal plasmid as an internal control. Cells were harvested $24 \mathrm{~h}$ post transfection and luciferase assay was performed as per the manufacturer's protocol (Promega, E2610). Readings for luminescence were taken in luminometer (Berthold, Sirius L).

The $\beta$-gal assay as performed as per Uchil et. al. (Uchil et. al., 2017). Briefly, $30 \mu 1$ of the cell extract was mixed with $3 \mu \mathrm{l} 100 \mathrm{X} \mathrm{Mg}^{+2}$ solution ( $0.1 \mathrm{M} \mathrm{MgCl}_{2}, 4.5 \mathrm{M}$ beta-mercaptoethanol), $66 \mu \mathrm{l} 1 \mathrm{X}$ ONPG (4 mg/ml ONPG in $0.1 \mathrm{M}$ phosphate buffer $\mathrm{pH} 7.5$ ) and $201 \mu \mathrm{l} 0.1 \mathrm{M}$ sodium phosphate, $\mathrm{pH} 7.5$. The reactions were incubated for 30 minutes to a few hours at $37^{\circ} \mathrm{C}$ until a faint yellow color developed. The reactions were stopped by adding $500 \mu 11 \mathrm{M} \mathrm{Na}_{2} \mathrm{CO}_{3}$ and the absorbance was recorded at $420 \mathrm{~nm}$ in a spectrophotometer.

\section{RNA isolation, qPCR and Western Blotting}

Total RNA was isolated from cells or tissues using RNAiso Plus (Takara Bio) for analysis by qRT-PCR as per the manufacturer's protocol. Real-time PCR was performed using SyBr green mix (Takara) in Realtime PCR machine (BioRad CFX96).

Cells or tissues were lysed in five times volume of RIPA buffer (150 mM sodium chloride, $1.0 \%$ NP-40 or Triton X-100, 0.5\% sodium deoxycholate, $0.1 \%$ SDS, 50 mM Tris-HCl pH 8.0, $1 \mathrm{mM}$ EDTA, $0.5 \mathrm{mM}$ EGTA) supplemented with $1 \mathrm{mM}$ PMSF and $1 \mathrm{X}$ mammalian protease 
699

700

701

702

703

704

705

706

707

708

709

710

711

712

713

714

715

716

717

718

719

720

721

722

723

724

725

726

727

728

inhibitor cocktail for 15 minutes on ice with occasional vortexing. Protein concentration was estimated using Bradford reagent. Samples were resolved on 10-12\% SDS-PAGE gel, transferred onto nitrocellulose membrane, incubated with primary and secondary antibodies and analyzed using chemiluminescence (Millipore, Luminata Forte, WBLUF0100) and exposure to X-ray films.

\section{FIMO analysis}

$3 \mathrm{~kb}$ promoter sequence of Mrhl (upstream from its TSS) was taken along with the motifs for PAX6 binding as described in a report by Xie and Cvekl (Xie and Cvek1, 2011). FIMO (Find Individual Motif Occurrences) (Grant et. al., 2011) scanning was then performed with a default cutoff value of $1 \mathrm{E}-04$.

\section{Promoter analysis}

GPMiner (Lee et. al., 2012) and JASPAR (Mathelier et. al., 2014) programs were used to analyze $3 \mathrm{~kb}$ upstream of transcription start site (TSS) of Mrhl. SnapGene software was used to map the binding sites of various TFs on the promoter region.

\section{Acknowledgements}

We thank Suma B.S of the Confocal Imaging Facility, Dr. R.G Prakash of the Animal Facility and Anitha G. of the Sequencing Facility at JNCASR, India. M.R.S Rao acknowledges Department of Science and technology, Govt of India for SERB Distinguished Fellowship and SERB- YOS (Year of Science Chair Professorship). Debosree Pal thanks University Grants Commission, Govt. of India and JNCASR, India for her PhD fellowship. Sangeeta Dutta thanks Department of Biotechnology, Govt. of India for her postdoctoral fellowship.

\section{Competing Interests}

The authors declare that they have no competing interests.

\section{Funding}

This work was financially supported by Department of Biotechnology, Govt. of India (Grant Numbers: BT/01/COE/07/09 and DBT/INF/22/SP27679/2018). M.R.S.R. acknowledges Department of Science and Technology for J. C. Bose and S.E.R.B. Distinguished fellowships and The Year of Science Chair professorship. 


\section{Author CRediT Statement:}

Conceptualization: M.R.S., D.P. Methodology: D.P., S.D., D.P.I., M.R.S. Software: U.B. Validation: S.D. Formal Analysis: D.P., S.D., D.P.I., U.B. Investigation: D.P., S.D., D.P.I., U.B. Resources: M.R.S. Data Curation: D.P., U.B. Writing - Original draft and preparation: D.P., S.D. Writing - review and editing: M.R.S. Visualization: D.P., M.R.S. Supervision: M.R.S. Project administration: M.R.S. Funding acquisition: M.R.S.

\section{References}

1. Akhade, V.S., Arun, G., Donakonda, S. and Satyanarayana Rao, M.R. (2014). Genome wide chromatin occupancy of mrhl RNA and its role in gene regulation in mouse spermatogonial cells. RNA biology, 11(10), pp.1262-1279.

2. Akhade, V.S., Dighe, S.N., Kataruka, S. and Rao, M.R.S. (2016). Mechanism of Wnt signaling induced down regulation of mrhl long non-coding RNA in mouse spermatogonial cells. Nucleic acids research, 44(1), pp.387-401.

3. Akhade, V.S., Pal, D. and Kanduri, C. (2017). Long noncoding RNA: genome organization and mechanism of action. Long Non Coding RNA Biology, pp.47-74.

4. Alammari, F. (2019). KAP1-Paupar lncRNA chromatin regulatory complex controls subventricular zone neurogenesis. PhD thesis, University of Oxford, Oxford, United Kingdom.

5. Andersen, R.E. (2019). The Novel Long Noncoding RNA Pnky Regulates Neurogenesis and Neural Stem Cell Maintenance In Vivo. PhD thesis, University of California, San Francisco, USA.

6. Antoniou, D., Stergiopoulos, A. and Politis, P.K. (2014). Recent advances in the involvement of long non-coding RNAs in neural stem cell biology and brain pathophysiology. Frontiers in physiology, 5, p.155.

7. Arun, G., Akhade, V.S., Donakonda, S. and Rao, M.R.S. (2012). mrhl RNA, a long noncoding RNA, negatively regulates Wnt signaling through its protein partner Ddx5/p68 in mouse spermatogonial cells. Molecular and cellular biology, 32(15), p.3140.

8. Bibel, M., Richter, J., Lacroix, E., and Barde, Y. A. (2007). Generation of a defined and uniform population of CNS progenitors and neurons from mouse embryonic stem cells. Nature protocols, 2(5), 1034. 
9. Bouchard, M., Grote, D., Craven, S. E., Sun, Q., Steinlein, P., and Busslinger, M. (2005). Identification of Pax2-regulated genes by expression profiling of the midhindbrain organizer region. Development, 132(11), 2633-2643.

10. Bouilloux, F., Thireau, J., Venteo, S., Farah, C., Karam, S., Dauvilliers, Y., Valmier, J., Copeland, NG., Jenkins, NA., Richard, S., et. al. (2016). Loss of the transcription factor Meis1 prevents sympathetic neurons target-field innervation and increases susceptibility to sudden cardiac death. Elife, 5, e11627.

11. Briggs, J.A., Wolvetang, E.J., Mattick, J.S., Rinn, J.L. and Barry, G. (2015). Mechanisms of long non-coding RNAs in mammalian nervous system development, plasticity, disease, and evolution. Neuron, 88(5), pp.861-877.

12. Chalei, V., Sansom, S.N., Kong, L., Lee, S., Montiel, J.F., Vance, K.W. and Ponting, C.P. (2014). The long non-coding RNA Dali is an epigenetic regulator of neural differentiation. elife, 3, p.e04530.

13. Chen, Y. and Tergaonkar, V. (2020). LncRNAs: Master Regulators in Disease and Cancer. Proceedings of the Singapore National Academy of Science, 14(02), pp.79-89.

14. Chenn, A., and Walsh, C. A. (2002). Regulation of cerebral cortical size by control of cell cycle exit in neural precursors. Science, 297(5580), 365-369.

15. Choudhury, S.R., Dutta, S., Bhaduri, U. and Rao, S.M. (2020). LncRNA Hmrhl regulates expression of cancer related genes in Chronic Myelogenous Leukemia through chromatin association. bioRxiv doi: https://doi.org/10.1101/2020.09.17.301770.

16. Cotney, J. L., and Noonan, J. P. (2015). Chromatin immunoprecipitation with fixed animal tissues and preparation for high-throughput sequencing. Cold Spring Harbor protocols, 2015(2), pdb-prot084848.

17. Cui, Y., Yin, Y., Xiao, Z., Zhao, Y., Chen, B., Yang, B., Xu, B., Song, H., Zou, Y., Ma, X. and Dai, J. (2019). LncRNA Neat1 mediates miR-124-induced activation of $\mathrm{Wnt} / \beta$-catenin signaling in spinal cord neural progenitor cells. Stem cell research \& therapy, 10(1), pp.1-11.

18. de Planell-Saguer, M., Rodicio, M. C., and Mourelatos, Z. (2010). Rapid in situ codetection of noncoding RNAs and proteins in cells and formalin-fixed paraffinembedded tissue sections without protease treatment. Nature protocols, 5(6), 1061.

19. Derrien, T., Johnson, R., Bussotti, G., Tanzer, A., Djebali, S., Tilgner, H., Guernec, G., Martin, D., Merkel, A., Knowles, D.G. and Lagarde, J. (2012). The GENCODE 
v7 catalog of human long noncoding RNAs: analysis of their gene structure, evolution, and expression. Genome research, 22(9), pp.1775-1789.

20. Dinger, M.E., Amaral, P.P., Mercer, T.R., Pang, K.C., Bruce, S.J., Gardiner, B.B., Askarian-Amiri, M.E., Ru, K., Soldà, G., Simons, C. and Sunkin, S.M. (2008). Long noncoding RNAs in mouse embryonic stem cell pluripotency and differentiation. Genome research, 18(9), pp.1433-1445.

21. Engreitz, J.M., Haines, J.E., Perez, E.M., Munson, G., Chen, J., Kane, M., McDonel, P.E., Guttman, M. and Lander, E.S. (2016). Local regulation of gene expression by lncRNA promoters, transcription and splicing. Nature, 539(7629), pp.452-455.

22. Fatima, R., Choudhury, S.R., Divya, T.R., Bhaduri, U. and Rao, M.R.S. (2019). A novel enhancer RNA, Hmrhl, positively regulates its host gene, phkb, in chronic myelogenous leukemia. Non-coding RNA research, 4(3), pp.96-108.

23. Feng, J., Bi, C., Clark, B.S., Mady, R., Shah, P. and Kohtz, J.D. (2006). The Evf-2 noncoding RNA is transcribed from the Dlx-5/6 ultraconserved region and functions as a Dlx-2 transcriptional coactivator. Genes \& development, 20(11), pp.1470-1484.

24. Fullard, J.F., Hauberg, M.E., Bendl, J., Egervari, G., Cirnaru, M.D., Reach, S.M., Motl, J., Ehrlich, M.E., Hurd, Y.L. and Roussos, P. (2018). An atlas of chromatin accessibility in the adult human brain. Genome research, 28(8), pp.1243-1252.

25. Gaiano, N., Nye, J. S., and Fishell, G. (2000). Radial glial identity is promoted by Notch1 signaling in the murine forebrain. Neuron, 26(2), 395-404.

26. Ganesan, G. and Rao, S.M. (2008). A novel noncoding RNA processed by Drosha is restricted to nucleus in mouse. Rna, 14(7), pp.1399-1410.

27. Goff, L.A., Groff, A.F., Sauvageau, M., Trayes-Gibson, Z., Sanchez-Gomez, D.B., Morse, M., Martin, R.D., Elcavage, L.E., Liapis, S.C., Gonzalez-Celeiro, M. and Plana, O. (2015). Spatiotemporal expression and transcriptional perturbations by long noncoding RNAs in the mouse brain. Proceedings of the National Academy of Sciences, 112(22), pp.6855-6862.

28. Grant, C. E., Bailey, T. L., and Noble, W. S. (2011). FIMO: scanning for occurrences of a given motif. Bioinformatics, 27(7), 1017-1018.

29. Hart, R.P. and Goff, L.A. (2016). Long noncoding RNAs: central to nervous system development. International Journal of Developmental Neuroscience, 55, pp.109-116.

30. Hartford, C.C.R. and Lal, A. (2020). When long noncoding becomes protein coding. Molecular and Cellular Biology, 40(6). 
31. Hezroni, H., Ben-Tov Perry, R., Gil, N., Degani, N. and Ulitsky, I. (2020). Regulation of neuronal commitment in mouse embryonic stem cells by the Reno1/Bahcc1 locus. EMBO reports, 21(11), p.e51264.

32. Huang, T., Wang, G., Yang, L., Peng, B., Wen, Y., Ding, G. and Wang, Z. (2017). Transcription factor YY1 modulates lung cancer progression by activating lncRNAPVT1. DNA and cell biology, 36(11), pp.947-958.

33. Imayoshi, I., Sakamoto, M., Yamaguchi, M., Mori, K., and Kageyama, R. (2010). Essential roles of Notch signaling in maintenance of neural stem cells in developing and adult brains. Journal of Neuroscience, 30(9), 3489-3498.

34. Iyer, M.K., Niknafs, Y.S., Malik, R., Singhal, U., Sahu, A., Hosono, Y., Barrette, T.R., Prensner, J.R., Evans, J.R., Zhao, S. and Poliakov, A. (2015). The landscape of long noncoding RNAs in the human transcriptome. Nature genetics, 47(3), pp.199208.

35. Jarroux, J., Morillon, A. and Pinskaya, M. (2017). History, discovery, and classification of lncRNAs. Long Non Coding RNA Biology, pp.1-46.

36. Kadakkuzha, B.M., Liu, X.A., McCrate, J., Shankar, G., Rizzo, V., Afinogenova, A., Young, B., Fallahi, M., Carvalloza, A.C., Raveendra, B. and Puthanveettil, S.V. (2015). Transcriptome analyses of adult mouse brain reveal enrichment of lncRNAs in specific brain regions and neuronal populations. Frontiers in cellular neuroscience, 9 , p.63.

37. Kamachi, Y., Uchikawa, M., Tanouchi, A., Sekido, R., and Kondoh, H. (2001). Pax6 and SOX2 form a co-DNA-binding partner complex that regulates initiation of lens development. Genes \& development, 15(10), 1272-1286.

38. Kirkeby, A., Grealish, S., Wolf, D.A., Nelander, J., Wood, J., Lundblad, M., Lindvall, O. and Parmar, M. (2012). Generation of regionally specified neural progenitors and functional neurons from human embryonic stem cells under defined conditions. Cell reports, 1(6), 703-714.

39. Knauss, J.L., Miao, N., Kim, S.N., Nie, Y., Shi, Y., Wu, T., Pinto, H.B., Donohoe, M.E. and Sun, T. (2018). Long noncoding RNA Sox2ot and transcription factor YY1 co-regulate the differentiation of cortical neural progenitors by repressing Sox2. Cell death \& disease, 9(8), pp.1-13.

40. Kopp, F. and Mendell, J.T. (2018). Functional classification and experimental dissection of long noncoding RNAs. Cell, 172(3), pp.393-407. 
41. Lee, T. Y., Chang, W. C., Hsu, J. B. K., Chang, T. H., and Shien, D. M. (2012). GPMiner: an integrated system for mining combinatorial cis-regulatory elements in mammalian gene group. In BMC genomics, 13,1, pp. 1-12.

42. Li, L., Zhuang, Y., Zhao, X. and Li, X. (2019). Long non-coding RNA in neuronal development and neurological disorders. Frontiers in genetics, 9, p.744.

43. Liau, W.S., Samaddar, S., Banerjee, S. and Bredy, T.W. (2021). On the functional relevance of spatiotemporally-specific patterns of experience-dependent long noncoding RNA expression in the brain. RNA biology, pp.1-12.

44. Liu, J., Wu, X., Zhang, H., Pfeifer, G. P., and Lu, Q. (2017). Dynamics of RNA polymerase II pausing and bivalent histone $\mathrm{H} 3$ methylation during neuronal differentiation in brain development. Cell reports, 20(6), 1307-1318.

45. Lv, J., Cui, W., Liu, H., He, H., Xiu, Y., Guo, J., Liu, H., Liu, Q., Zeng, T., Chen, Y. and Zhang, Y. (2013). Identification and characterization of long non-coding RNAs related to mouse embryonic brain development from available transcriptomic data. PloS one, 8(8), p.e71152.

46. Machon, O., Van Den Bout, C. J., Backman, M., Kemler, R., and Krauss, S. (2003). Role of $\beta$-catenin in the developing cortical and hippocampal neuroepithelium. Neuroscience, 122(1), 129-143.

47. Marchese, F.P., Raimondi, I. and Huarte, M. (2017). The multidimensional mechanisms of long noncoding RNA function. Genome biology, 18(1), pp.1-13.

48. Mathelier, A., Zhao, X., Zhang, A.W., Parcy, F., Worsley-Hunt, R., Arenillas, D.J., Buchman, S., Chen, C.Y., Chou, A., Ienasescu, H. and Lim, J. (2014). JASPAR 2014: an extensively expanded and updated open-access database of transcription factor binding profiles. Nucleic acids research, 42(D1), D142-D147

49. Mercer, T.R., Dinger, M.E., Sunkin, S.M., Mehler, M.F. and Mattick, J.S. (2008). Specific expression of long noncoding RNAs in the mouse brain. Proceedings of the National Academy of Sciences, 105(2), pp.716-721.

50. Mizutani, K. I., Yoon, K., Dang, L., Tokunaga, A., and Gaiano, N. (2007). Differential Notch signalling distinguishes neural stem cells from intermediate progenitors. Nature, 449(7160), 351-355.

51. Mohamed, J.S., Gaughwin, P.M., Lim, B., Robson, P. and Lipovich, L. (2010). Conserved long noncoding RNAs transcriptionally regulated by Oct4 and Nanog modulate pluripotency in mouse embryonic stem cells. Rna, 16(2), pp.324-337. 
52. Ng, S.Y., Bogu, G.K., Soh, B.S. and Stanton, L.W. (2013). The long noncoding RNA RMST interacts with SOX2 to regulate neurogenesis. Molecular cell, 51(3), pp.349359.

53. Nishant, K.T., Ravishankar, H. and Rao, M.R.S. (2004). Characterization of a mouse recombination hot spot locus encoding a novel non-protein-coding RNA. Molecular and cellular biology, 24(12), p.5620.

54. Owa, T., Taya, S., Miyashita, S., Yamashita, M., Adachi, T., Yamada, K., Yokoyama, M., Aida, S., Nishioka, T., Inoue, Y.U. and Goitsuka, R. (2018). Meis1 coordinates cerebellar granule cell development by regulating Pax6 transcription, BMP signaling and Atoh1 degradation. Journal of Neuroscience, 38(5), 1277-1294.

55. Pal, D., Neha, C.V., Bhaduri, U., Zenia, Z., Dutta, S., Chidambaram, S. and Rao, M.R.S. (2021). LncRNA Mrhl orchestrates differentiation programs in mouse embryonic stem cells through chromatin mediated regulation. Stem Cell Research, 53, p.102250.

56. Pijnappel, W. P., Baltissen, M. P., and Timmers, H. M. (2013). Protocol for lentiviral knock down in mouse ES cells. Doi 10.1038/protex.2013.036

57. Pinson, J., Mason, J. O., Simpson, T. I., and Price, D. J. (2005). Regulation of the Pax6: Pax6 (5a) mRNA ratio in the developing mammalian brain. BMC developmental biology, 5(1), 1-4.

58. Plachta, N., Bibel, M., Tucker, K. L., and Barde, Y. A. (2004). Developmental potential of defined neural progenitors derived from mouse embryonic stem cells. Development, 131(21), 5449-5456.

59. Ramos, A.D., Andersen, R.E., Liu, S.J., Nowakowski, T.J., Hong, S.J., Gertz, C.C., Salinas, R.D., Zarabi, H., Kriegstein, A.R. and Lim, D.A. (2015). The long noncoding RNA Pnky regulates neuronal differentiation of embryonic and postnatal neural stem cells. Cell stem cell, 16(4), pp.439-447.

60. Roberts, T.C., Morris, K.V. and Wood, M.J. (2014). The role of long non-coding RNAs in neurodevelopment, brain function and neurological disease. Philosophical Transactions of the Royal Society B: Biological Sciences, 369(1652), p.20130507.

61. Rosa, A. and Ballarino, M. (2016). Long noncoding RNA regulation of pluripotency. Stem Cells International, 2016.

62. Sakamoto, M., Hirata, H., Ohtsuka, T., Bessho, Y., and Kageyama, R. (2003). The basic helix-loop-helix genes Hesr1/Hey1 and Hesr2/Hey2 regulate maintenance of 
neural precursor cells in the brain. Journal of Biological Chemistry, 278(45), 4480844815.

63. Sansom, S.N., Griffiths, D.S., Faedo, A., Kleinjan, D.J., Ruan, Y., Smith, J., Van Heyningen, V., Rubenstein, J.L. and Livesey, F.J. (2009). The level of the transcription factor Pax6 is essential for controlling the balance between neural stem cell self-renewal and neurogenesis. PLoS Genet, 5(6), e1000511.

64. Stamou, M., Ng, S.Y., Brand, H., Wang, H., Plummer, L., Best, L., Havlicek, S., Hibberd, M., Khor, C.C., Gusella, J. and Balasubramanian, R. (2020). A balanced translocation in Kallmann Syndrome implicates a long noncoding RNA, RMST, as a GnRH neuronal regulator. The Journal of Clinical Endocrinology \& Metabolism, 105(3), pp.e231-e244.

65. Su, Z., Zhang, Y., Liao, B., Zhong, X., Chen, X., Wang, H., Guo, Y., Shan, Y., Wang, L. and Pan, G. (2018). Antagonism between the transcription factors NANOG and OTX2 specifies rostral or caudal cell fate during neural patterning transition. Journal of Biological Chemistry, 293(12), 4445-4455.

66. Sun, J., Rockowitz, S., Xie, Q., Ashery-Padan, R., Zheng, D., and Cvekl, A. (2015). Identification of in vivo DNA-binding mechanisms of Pax6 and reconstruction of Pax6dependent gene regulatory networks during forebrain and lens development. Nucleic acids research, 43(14), 6827-6846.

67. Sun, J., Zhao, Y., McGreal, R., Cohen-Tayar, Y., Rockowitz, S., Wilczek, C., Ashery-Padan, R., Shechter, D., Zheng, D. and Cvekl, A. (2016). Pax6 associates with H3K4-specific histone methyltransferases Mll1, Mll2, and Set1a and regulates H3K4 methylation at promoters and enhancers. Epigenetics \& chromatin, 9(1), pp.118.

68. Sun, M. and Kraus, W.L. (2015). From discovery to function: the expanding roles of long noncoding RNAs in physiology and disease. Endocrine reviews, 36(1), pp.25-64.

69. Sun, Z., Huang, G. and Cheng, H. (2019). Transcription factor Nrf2 induces the upregulation of lncRNA TUG1 to promote progression and adriamycin resistance in urothelial carcinoma of the bladder. Cancer management and research, 11, p.6079.

70. Thakurela, S., Tiwari, N., Schick, S., Garding, A., Ivanek, R., Berninger, B., and Tiwari, V. K. (2016). Mapping gene regulatory circuitry of Pax6 during neurogenesis. Cell discovery, 2(1), 1-22.

71. Tian, K., Wang, A., Wang, J., Li, W., Shen, W., Li, Y., Luo, Z., Liu, Y. and Zhou, Y. (2021). Transcriptome Analysis Identifies SenZfp536, a Sense LncRNA that 
Suppresses Self-renewal of Cortical Neural Progenitors. Neuroscience Bulletin, 37(2), pp.183-200.

72. Uchil, P. D., Nagarajan, A., and Kumar, P. (2017). Assay for $\beta$-galactosidase in extracts of mammalian cells. Cold Spring Harbor Protocols, 2017(10), pdbprot095778.

73. Vihma, H., Luhakooder, M., Pruunsild, P., and Timmusk, T. (2016). Regulation of different human NFAT isoforms by neuronal activity. Journal of neurochemistry, 137(3), 394-408.

74. Wang, H., Huo, X., Yang, X.R., He, J., Cheng, L., Wang, N., Deng, X., Jin, H., Wang, N., Wang, C. and Zhao, F. (2017). STAT3-mediated upregulation of lncRNA HOXD-AS1 as a ceRNA facilitates liver cancer metastasis by regulating SOX4. Molecular cancer, 16(1), 1-15.

75. Wapinski, O. and Chang, H.Y. (2011). Long noncoding RNAs and human disease. Trends in cell biology, 21(6), pp.354-361.

76. Wild, A. R., Sinnen, B. L., Dittmer, P. J., Kennedy, M. J., Sather, W. A., and Dell'Acqua, M. L. (2019). Synapse-to-Nucleus communication through NFAT is mediated by L-type Ca2+ Channel Ca2+ Spike Propagation to the Soma. Cell reports, 26(13), 3537-3550.

77. Wilusz, J.E., Sunwoo, H. and Spector, D.L. (2009). Long noncoding RNAs: functional surprises from the RNA world. Genes \& development, 23(13), pp.14941504.

78. Woodhead, G. J., Mutch, C. A., Olson, E. C., and Chenn, A. (2006). Cellautonomous $\beta$-catenin signaling regulates cortical precursor proliferation. Journal of Neuroscience, 26(48), 12620-12630.

79. Wu, S.C., Kallin, E.M. and Zhang, Y. (2010). Role of H3K27 methylation in the regulation of lncRNA expression. Cell research, 20(10), pp.1109-1116.

80. Wu, Z., Liu, X., Liu, L., Deng, H., Zhang, J., Xu, Q., Cen, B. and Ji, A. (2014). Regulation of lncRNA expression. Cellular \& molecular biology letters, 19(4), pp.561575.

81. Xie, Q., and Cvekl, A. (2011). The orchestration of mammalian tissue morphogenesis through a series of coherent feed-forward loops. Journal of Biological Chemistry, 286(50), 43259-43271.

82. Xie, Q., Yang, Y., Huang, J., Ninkovic, J., Walcher, T., Wolf, L., Vitenzon, A., Zheng, D., Götz, M., Beebe, D.C. and Zavadil, J. (2013). Pax6 interactions with 
chromatin and identification of its novel direct target genes in lens and forebrain. PLoS One, 8(1), e54507.

83. Xing, J., Liu, H., Jiang, W. and Wang, L. (2020). LncRNA-encoded peptide: functions and predicting methods. Frontiers in Oncology, 10.

84. Xu, Y., Xi, J., Wang, G., Guo, Z., Sun, Q., Lu, C., Ma, L., Wu, Y., Jia, W., Zhu, S. and Guo, X. (2021). PAUPAR and PAX6 sequentially regulate human embryonic stem cell cortical differentiation. Nucleic acids research, 49(4), pp.1935-1950.

85. Yamada, T., Urano-Tashiro, Y., Tanaka, S., Akiyama, H., and Tashiro, F. (2013). Involvement of crosstalk between Oct4 and Meis1a in neural cell fate decision. PLoS One, 8(2), e56997.

86. Yao, B., and Jin, P. (2014). Unlocking epigenetic codes in neurogenesis. Genes \& development, 28(12), 1253-1271.

87. Yoon, J.H., Abdelmohsen, K. and Gorospe, M. (2013). Posttranscriptional gene regulation by long noncoding RNA. Journal of molecular biology, 425(19), pp.37233730.

88. Zelinger, L., Karakülah, G., Chaitankar, V., Kim, J.W., Yang, H.J., Brooks, M.J. and Swaroop, A. (2017). Regulation of noncoding transcriptome in developing photoreceptors by rod differentiation factor NRL. Investigative ophthalmology \& visual science, 58(11), pp.4422-4435.

89. Zhang, P., Wu, W., Chen, Q. and Chen, M. (2019, a). Non-coding RNAs and their integrated networks. Journal of integrative bioinformatics, 16(3).

90. Zhang, L., Xue, Z., Yan, J., Wang, J., Liu, Q. and Jiang, H. (2019, b). LncRNA Riken-201 and Riken-203 modulates neural development by regulating the Sox6 through sequestering miRNAs. Cell proliferation, 52(3), p.e12573.

91. Zhang, L., Yan, J., Liu, Q., Xie, Z. and Jiang, H. (2019, c). LncRNA Rik-203 contributes to anesthesia neurotoxicity via microRNA-101a-3p and GSK-3 $\beta$-mediated neural differentiation. Scientific reports, 9(1), pp.1-12.

92. Zhao, Y., Liu, H., Zhang, Q. and Zhang, Y. (2020). The functions of long non-coding RNAs in neural stem cell proliferation and differentiation. Cell \& Bioscience, 10, pp.110. 
Figure 1. Mrhl is predominantly expressed in the neuronal progenitor population of the developing mouse embryonic brain. (A) qPCR data for Mrhl expression in embryonic and postnatal mouse brains. (B) qPCR for Mrhl expression across different regions of E14.5 brain along with region-specific markers. (C) RNA FISH for Mrhl and IF for PAX6 in E14.5 brain sections shows predominant expression of Mrhl in ventricular-subventricular (VZ/SVZ) zones of the brain concomitant with PAX6 nuclear expression. $\mathrm{CP}=$ cortical plate. (B) Analysis of available ChIP-Seq datasets for enrichment of RNA Pol II or histone modifications in Nestin+ cells from E15.5 cortices. Error bars indicate standard deviation from three independent experiments, with replicates in each $(\mathrm{n}=6-20) .{ }^{*} \mathrm{p}<0.05, * * \mathrm{p}<0.01, * * * \mathrm{p}<0.001$, student's $\mathrm{t}-$ test; Scale bar $=10 \mu \mathrm{m}$.

Figure 2. Mrhl expression in embryonic brain is recapitulated in an in vitro model. (A, B) qPCR analysis of Mrhl expression in RA versus vehicle treated EBs and 12 hours to D4 old maturing neurons, respectively. (C, D) RNA FISH for Mrhl and IF for NPC marker NESTIN and maturing neuron marker TUJ1 in EB sections and neurons. (E) ChIP-qPCR for H3K4me3 on proximal Mrhl promoter in RA treated EBs versus neurons at 24 hours. Error bars indicate standard deviation from three independent experiments, with replicates in each $(n=6) .{ }^{*} p<0.05$, ${ }^{* *} \mathrm{p}<0.01,{ }^{* * *} \mathrm{p}<0.001$, student's t-test; Scale bar $=10 \mu \mathrm{m}$.

Figure S1. (C) qPCR analysis of various markers for neuronal lineage in RA treated versus vehicle treated EBs. Ascl1 is a neuronal lineage marker. Nestin and Pax6 are NPC markers. Tuj1 is a maturing neuron marker. Gfap is an astrocyte lineage marker. (B) qPCR analysis of various markers for NPCs and neurons at different hours of differentiation show reduction in NPC markers and increase in neuron marker. (E) RNA FISH for Mrhl followed by IF for TUJ1 in neurons. Error bars indicate standard deviation from three independent experiments, with replicates in each $(\mathrm{n}=6) .{ }^{*} \mathrm{p}<0.05,{ }^{* *} \mathrm{p}<0.01,{ }^{*} * \mathrm{p}<0.001$, student's t-test; Scale bar $=10 \mu \mathrm{m}$.

Figure 3. Identification of potential transcriptional regulators for Mrhl during neuronal lineage development. (A) ChIP-Seq analysis for PAX6 and histone modifications on 3kb promoter of Mrhl, red bars and black arrows show our sites of interest. (B-D) Motifs for PAX6 on Mrhl promoter sites 1 to 4 as revealed by FIMO analysis. (E, F) ChIP-qPCR analysis for PAX6 enrichment on Mrhl promoter in E14.5 whole brain and RA treated EBs. Error bars indicate standard deviation from three independent experiments, with replicates in each $(n=6)$. 
1059

1060

1061

1062

1063

1064

1065

1066

1067

1068

1069

1070

1071

1072

1073

1074

1075

1076

1077

1078

1079

1080

1081

1082

1083

Figure S2. (A) GPMiner and JASPAR analysis for predicted TF binding sites on Mrhl 3kb promoter region; created by SnapGene. (B) IF for $\beta$-CATENIN in RA treated versus vehicle treated EBs and different time points of neuronal differentiation. (C) IF for NICD in RA versus vehicle treated EBs. (D) qRT-PCR analysis for genes upon DAPT treatment. Error bars indicate standard deviation from three independent experiments, with replicates in each $(n=6) .{ }^{*} p<0.05$, $* * \mathrm{p}<0.01,{ }^{* * *} \mathrm{p}<0.001$, student's t-test; Scale bar $=10 \mu \mathrm{m}$.

Figure 4. PAX6 is a major transcriptional regulator of Mrhl in neuronal progenitors. (A) EMSA for studying direct interaction of PAX6 on the Mrhl promoter sites 1-4. (B-E) Luciferase assays for different constructs of Mrhl promoter in the presence of exogenously expressed PAX6 and PAX6(5A). (F) Knockdown assay showing decrease in Mrhl expression upon inducing knockdown of PAX6. Error bars indicate standard deviation from three independent experiments, with replicates in each $(\mathrm{n}=6) .{ }^{*} \mathrm{p}<0.05, * * \mathrm{p}<0.01,{ }^{*} * \mathrm{p} p<0.001$, student's t-test.

Figure S3. (A) Sonication pattern for chromatin isolated from RA treated EBs and E14.5 whole brain. (B) Expression and validation of PAX6 and PAX6(5A) by western blot. (C) EMSA for PAX6(5A) binding to Mrhl promoter sites 1-4.

Figure 5. (A) Expression pattern of various NFAT isoforms vehicle versus RA treated EBs. (B) ChIP-qPCR for NFAT4 and MEIS1 binding on Mrhl promoter. (C) ChIP-WB for NFAT4 interaction with PAX6. (D) ChIP-WB for validating PAX6 interaction with NFAT4. Error bars indicate standard deviation from three independent experiments, with replicates in each $(n=6)$. $* \mathrm{p}<0.05, * * \mathrm{p}<0.01, * * * \mathrm{p}<0.001$, student's t-test.

Figure S4. (A) Expression levels of isoforms of NFAT in E14.5 whole brain and EBs; NTC:no template control. (B) qPCR showing NFAT4 expression amongst all isoforms in E14.5 brain as compared to P4 brains. Error bars indicate standard deviation from three independent experiments, with replicates in each $(n=6) .{ }^{*} \mathrm{p}<0.05,{ }^{*} \mathrm{p}<0.01,{ }^{*} * \mathrm{p}<0.001$, student's t-test. 
bioRxiv preprint doi: https://doi.org/10.1101/2021.06.23.449546; this version posted June 23, 2021. The copyright holder for this preprint (which was not certified by peer review) is the author/funder. All rights reserved. No reuse allowed without permission.

Figure 1

A

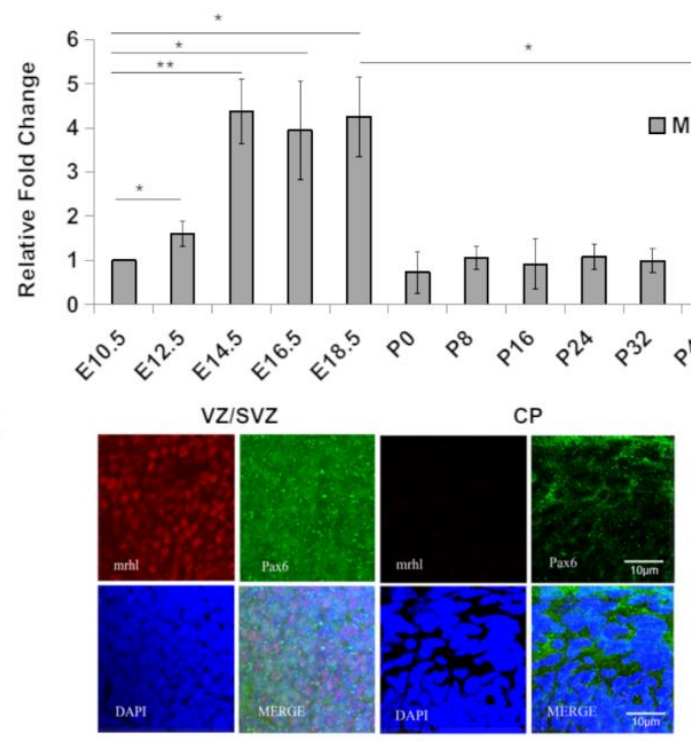

B

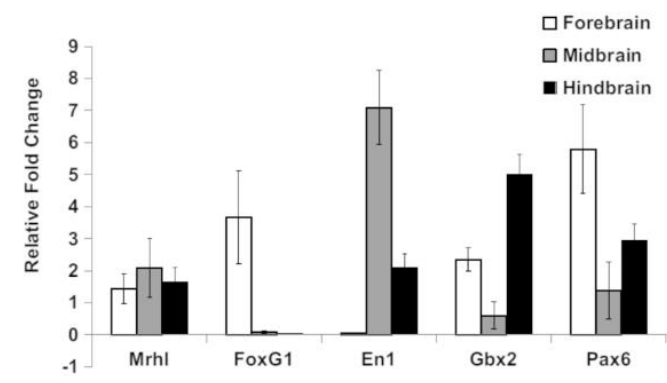

D

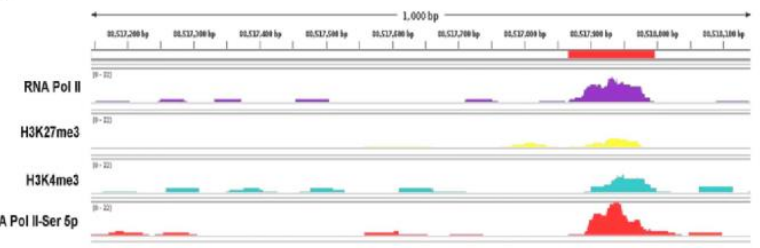

Figure 2

A

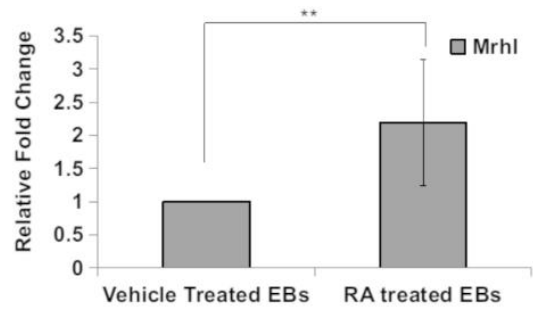

C

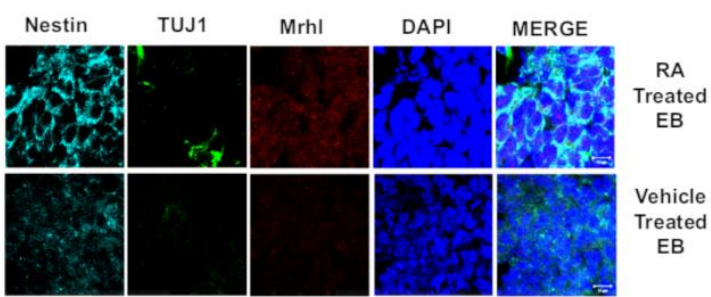

E

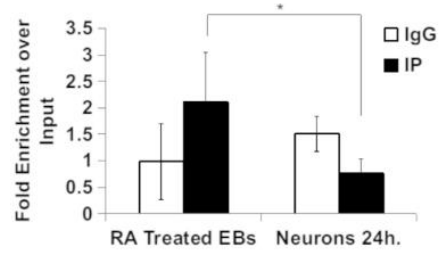

B

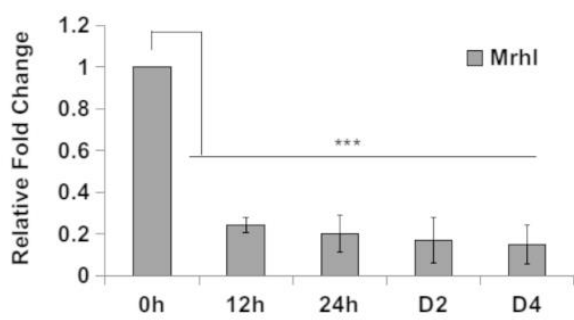

D

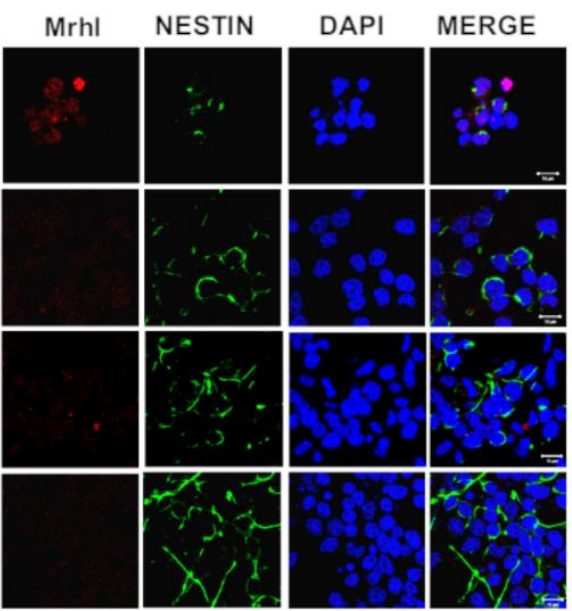

$\mathrm{NPC} \mathrm{Oh}$

Early Neurons $12 \mathrm{~h}$

Neurons $24 \mathrm{~h}$

Late Neurons D2 
bioRxiv preprint doi: https://doi.org/10.1101/2021.06.23.449546; this version posted June 23, 2021. The copyright holder for this preprint (which was not certified by peer review) is the author/funder. All rights reserved. No reuse allowed without permission.

\section{Figure 3}

A

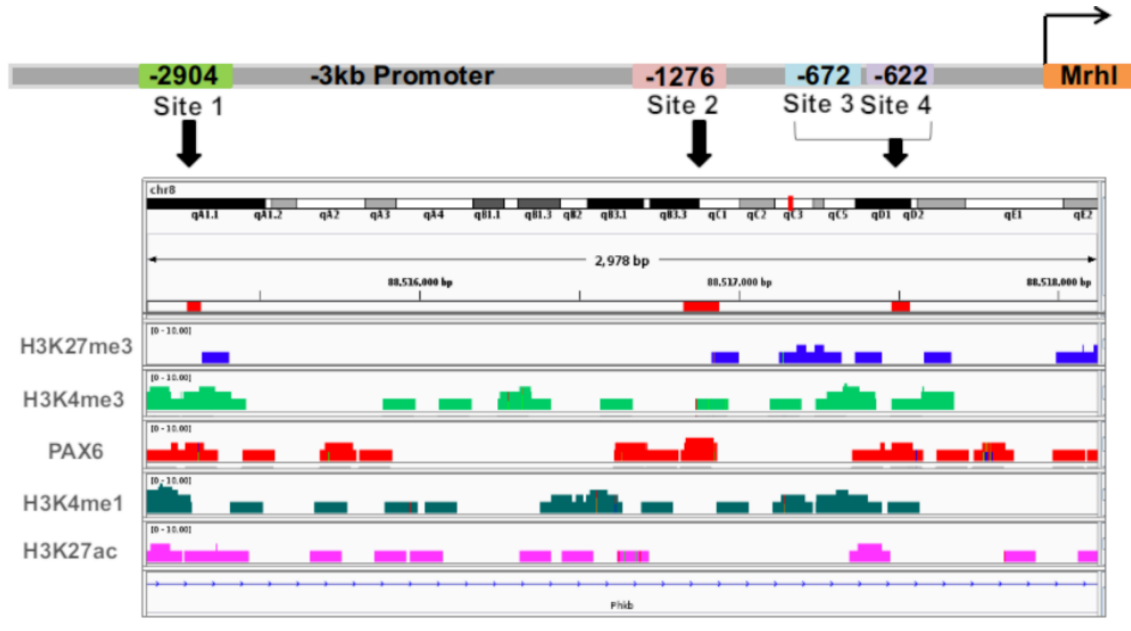

B

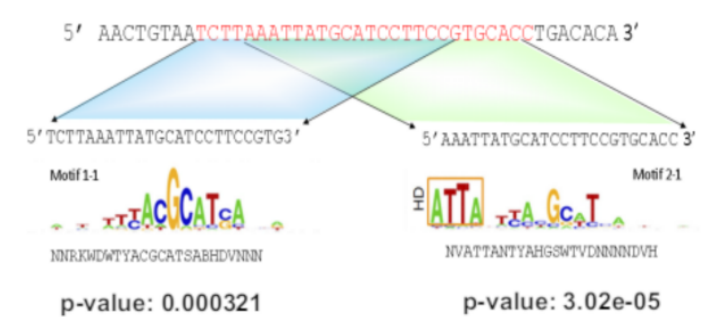

C

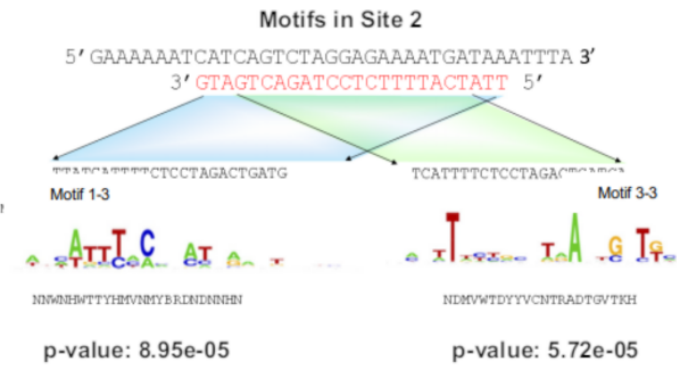

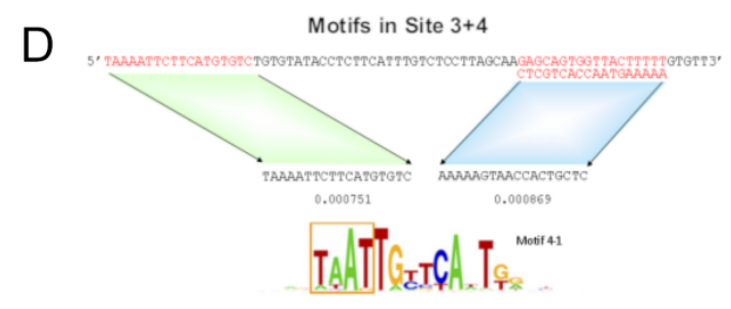

p-value: $0.000751 \quad p$-value: 0.000869

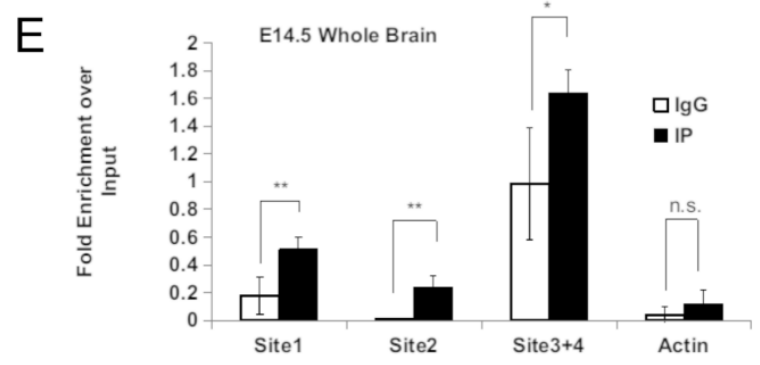

$\mathrm{F}$

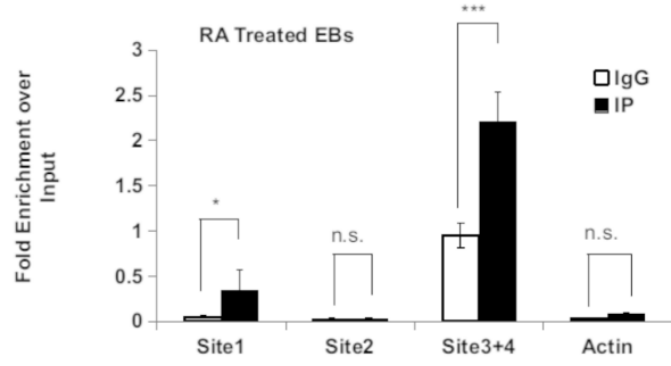


bioRxiv preprint doi: https://doi.org/10.1101/2021.06.23.449546; this version posted June 23, 2021. The copyright holder for this preprint (which was not certified by peer review) is the author/funder. All rights reserved. No reuse allowed without permission.

\section{Figure 4}

A

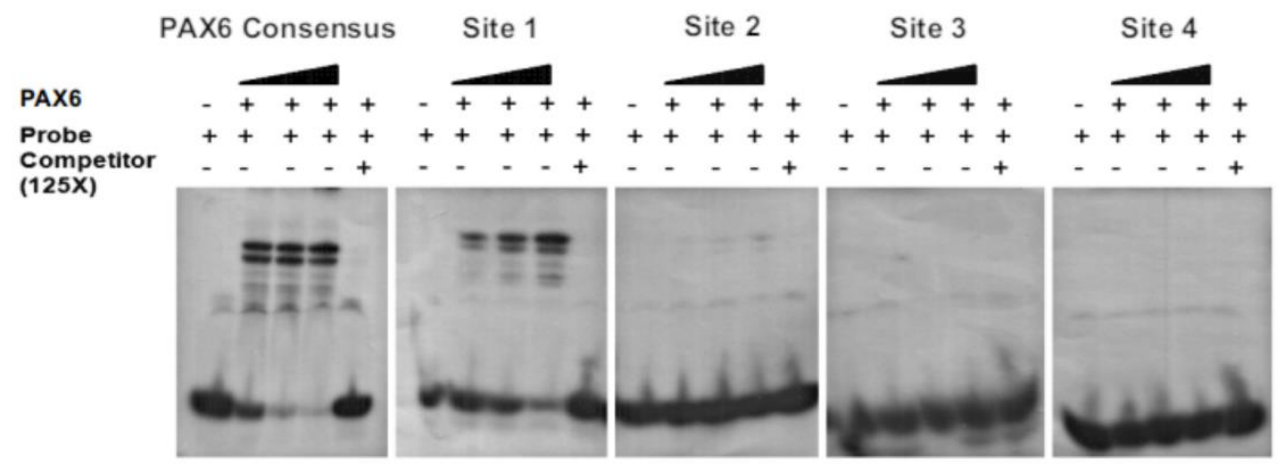

B
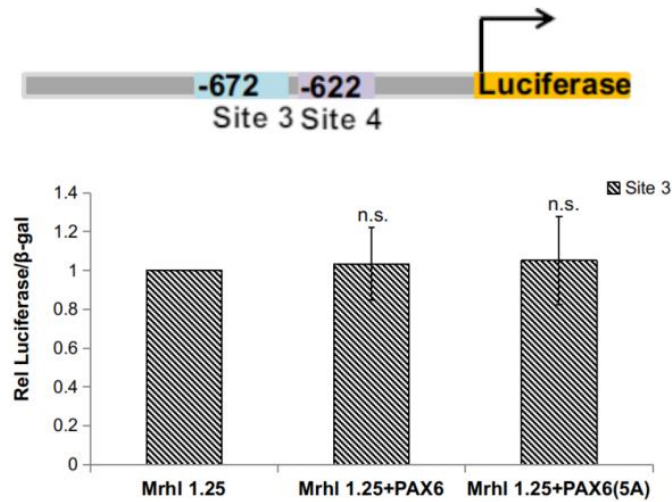

D
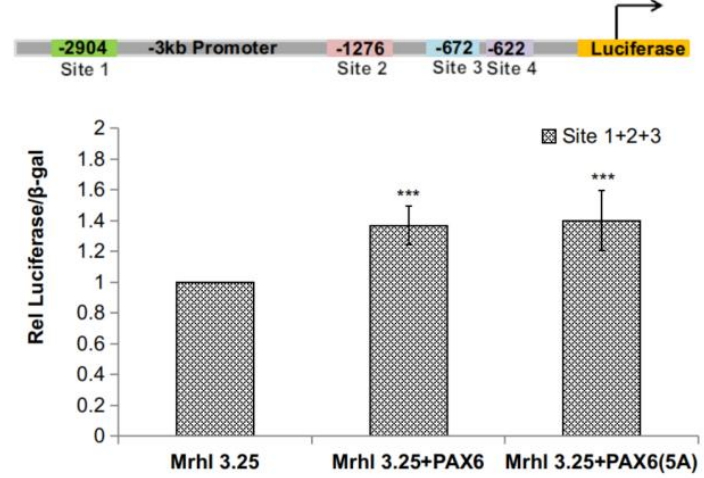

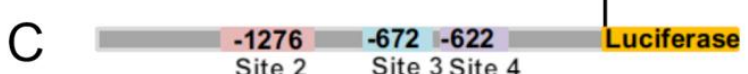

Site 2 Site 3 Site 4

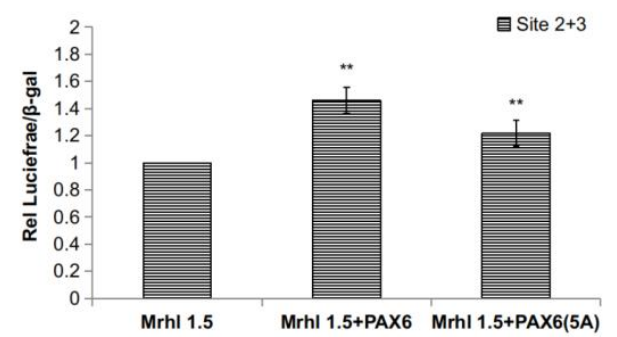

E

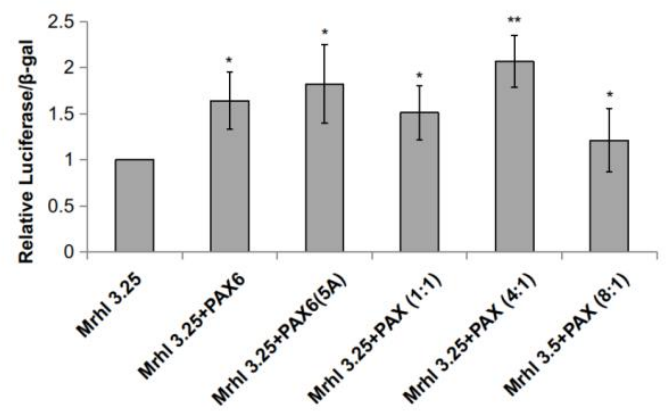

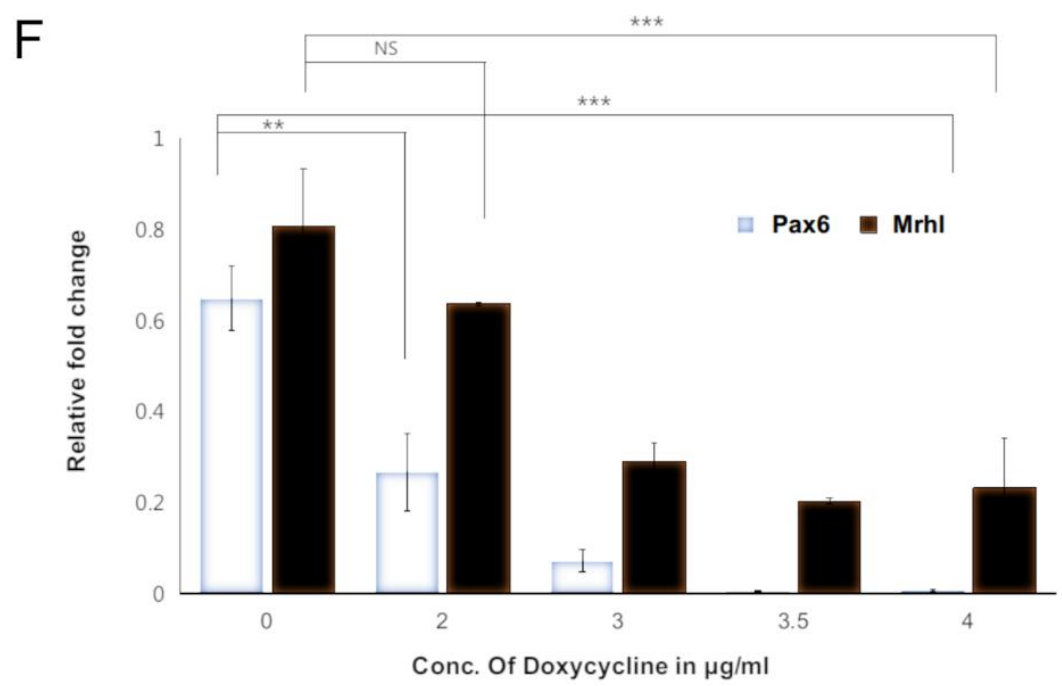




\section{Figure 5}

A

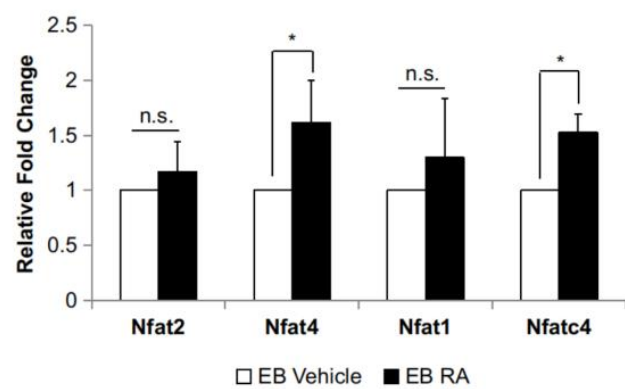

C

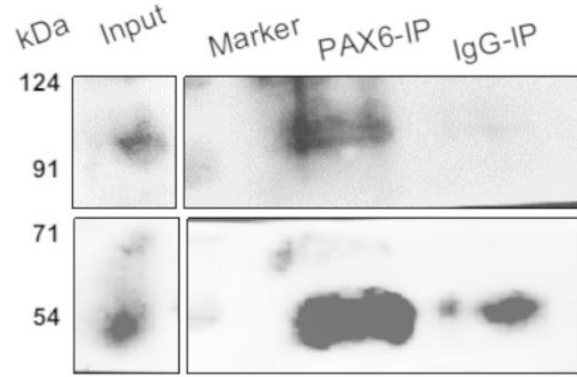

NFAT4

$E$

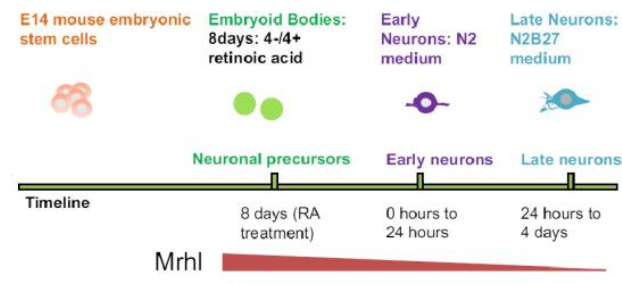

B
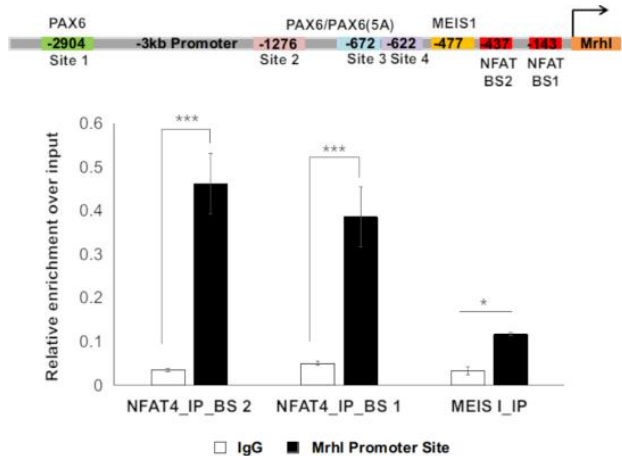

$\mathrm{D}$

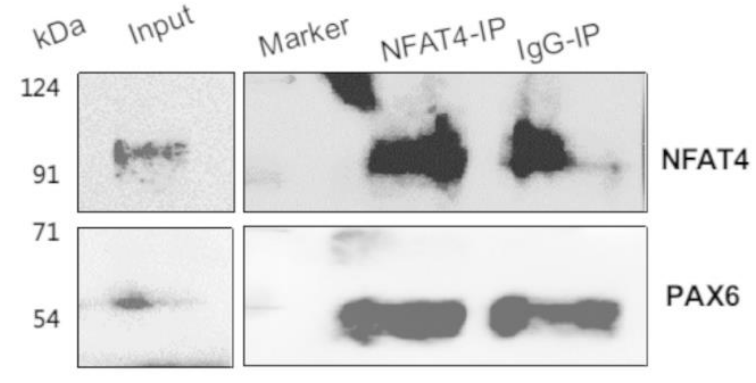

$\mathrm{F}$
Radial-glia like NPCs

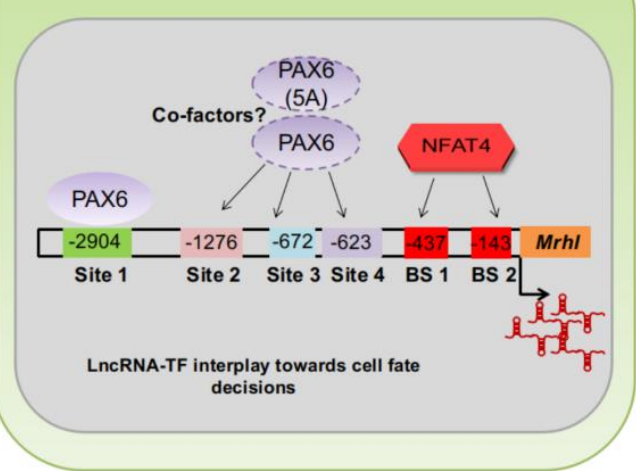




\section{Figure S1}

A

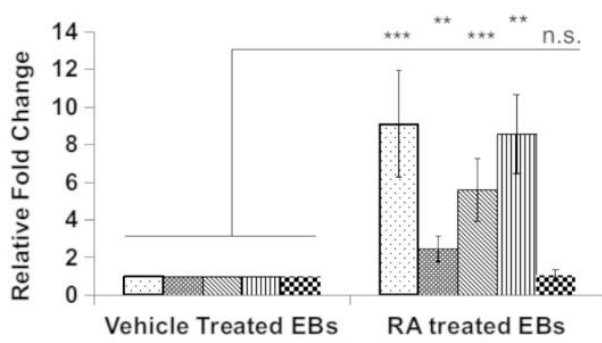

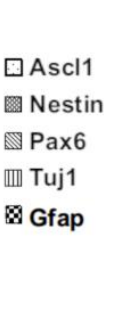

B

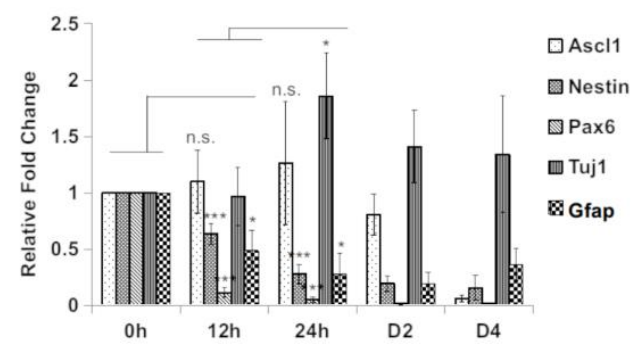

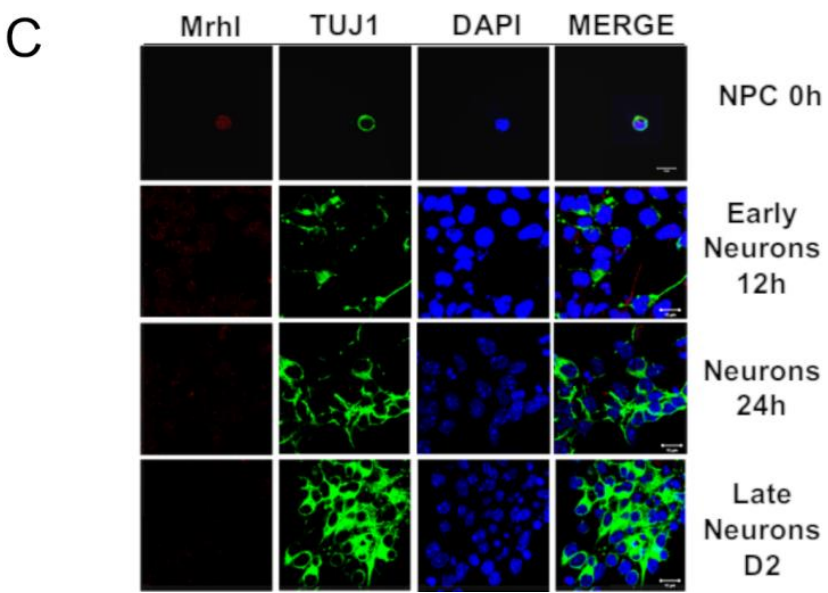




\section{Figure S2}

A

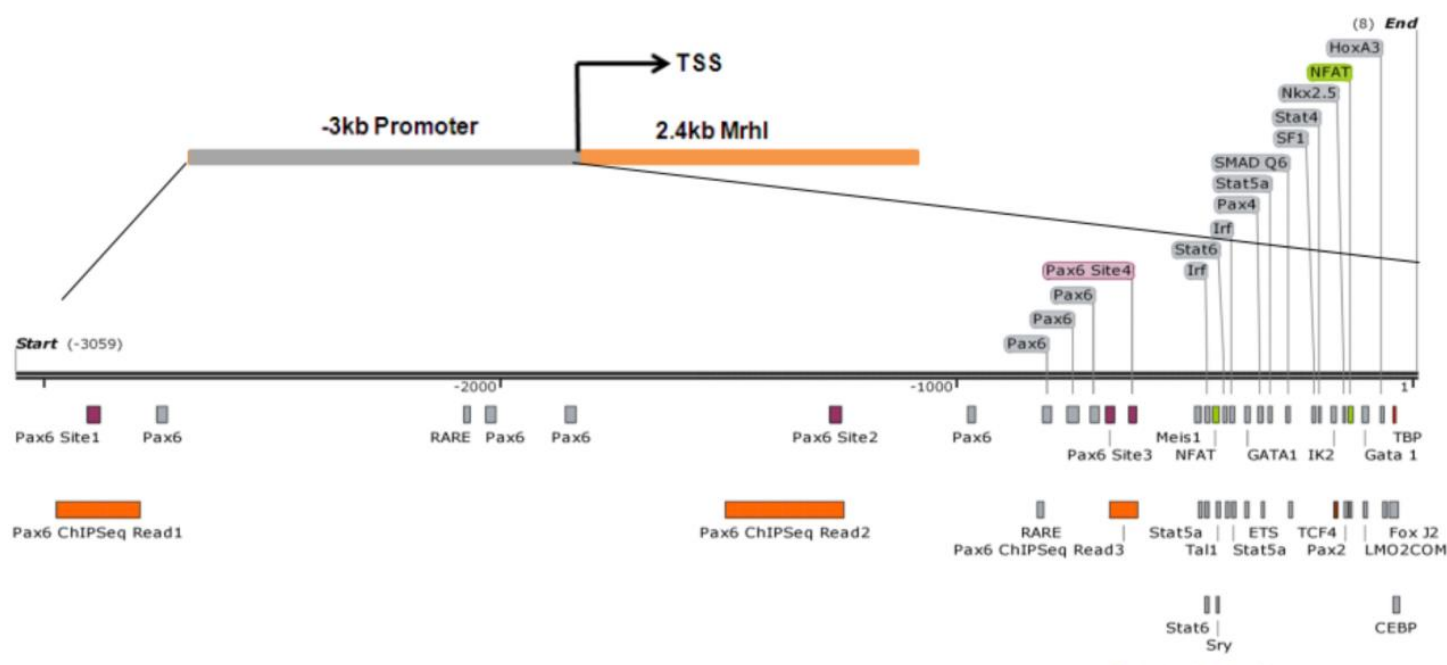

\section{Predicted Proneural /Neural TF Binding Sites on Mrhl Promoter}

Pax6 ChIPSeq Read1

B

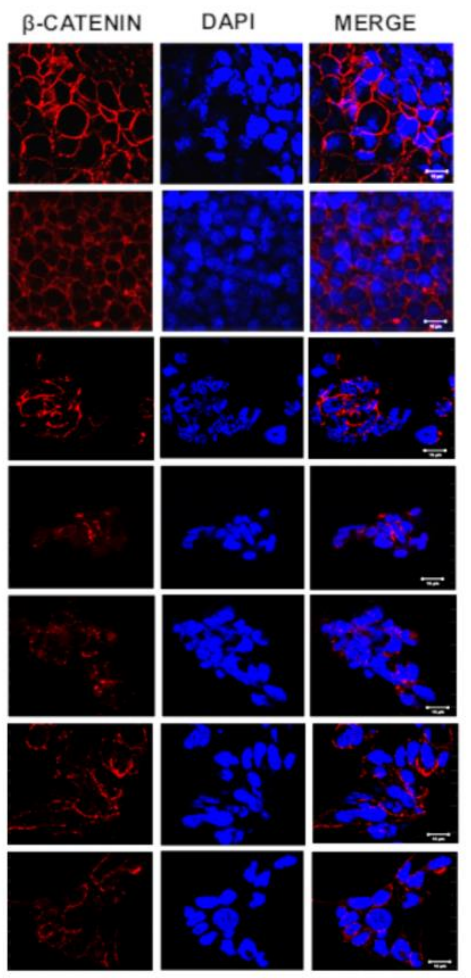

C
RA Treated

EBs

$2 \mathrm{~h}$

$4 \mathrm{~h}$

$8 h$

$16 \mathrm{~h}$

$24 \mathrm{~h}$

D
NICD
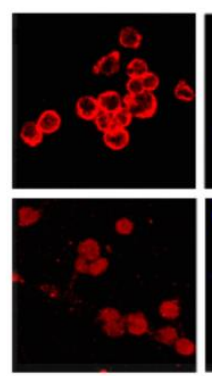

DAPI

MERGE
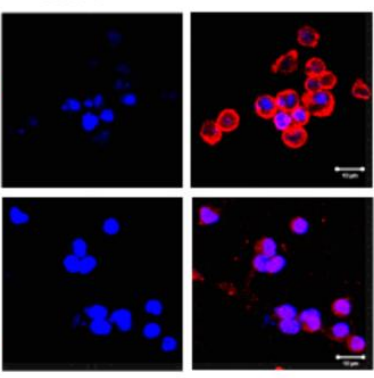

RA Treated

EBs

Treated

EBs

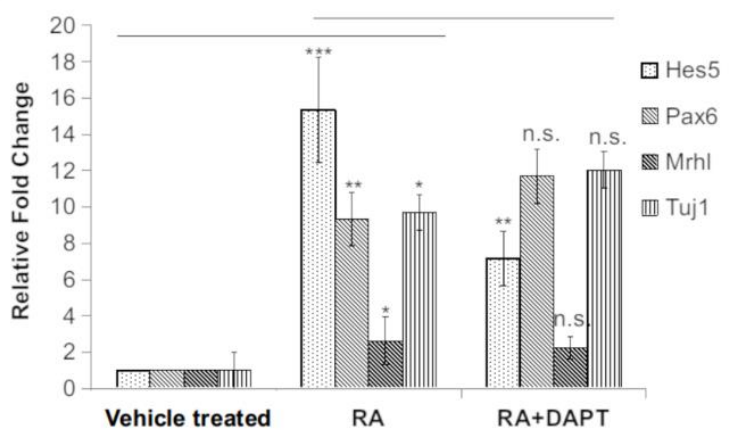


bioRxiv preprint doi: https://doi.org/10.1101/2021.06.23.449546; this version posted June 23, 2021. The copyright holder for this preprint (which was not certified by peer review) is the author/funder. All rights reserved. No reuse allowed without permission.

\section{Figure S3}

A

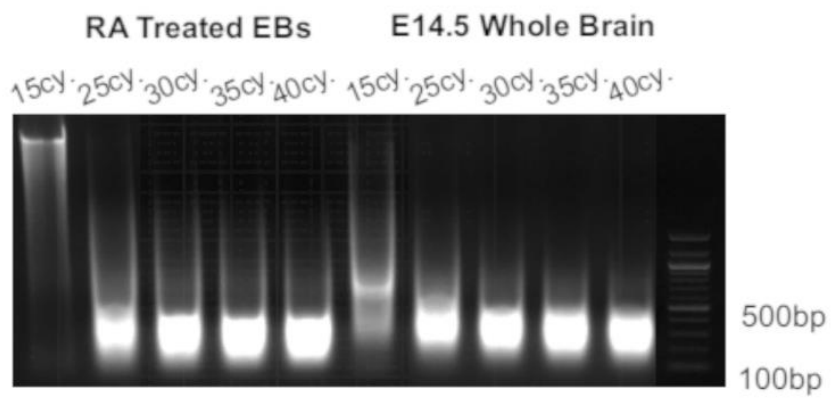

B

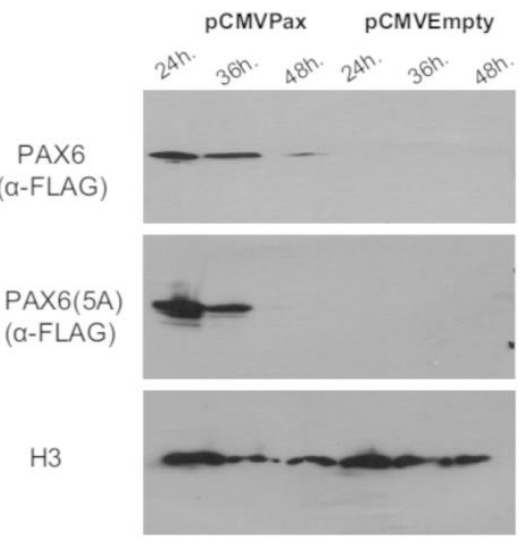

C

Site1

Site2

Site3

Site4

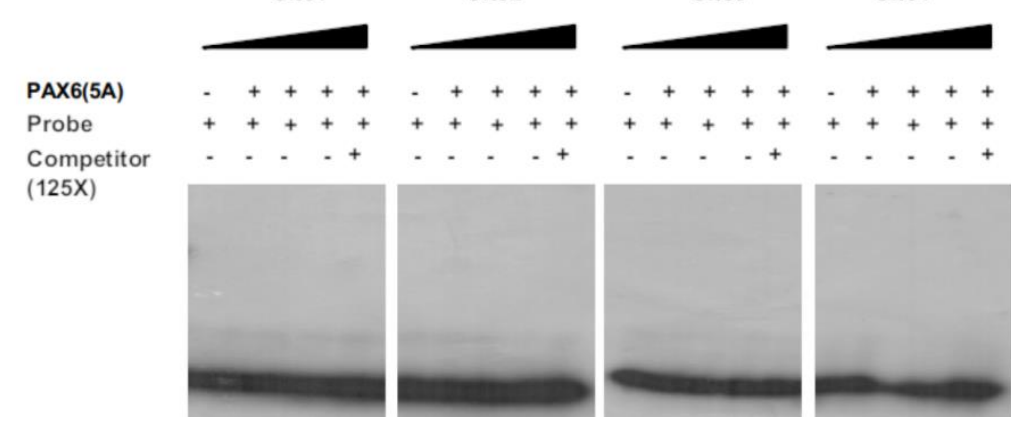




\section{Figure S4}

A

Nfat4/Nfatc3

Nfat2/Nfatc1
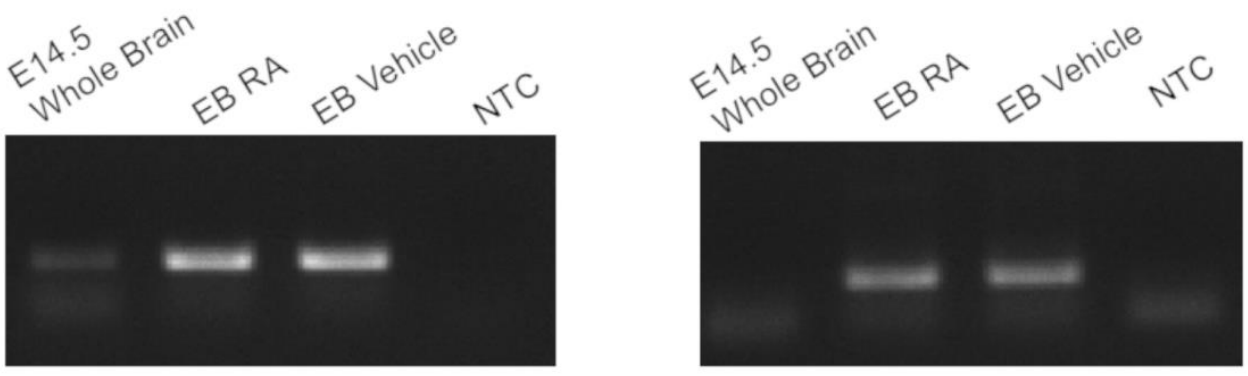

Nfatc4

Nfat1/Nfatc2
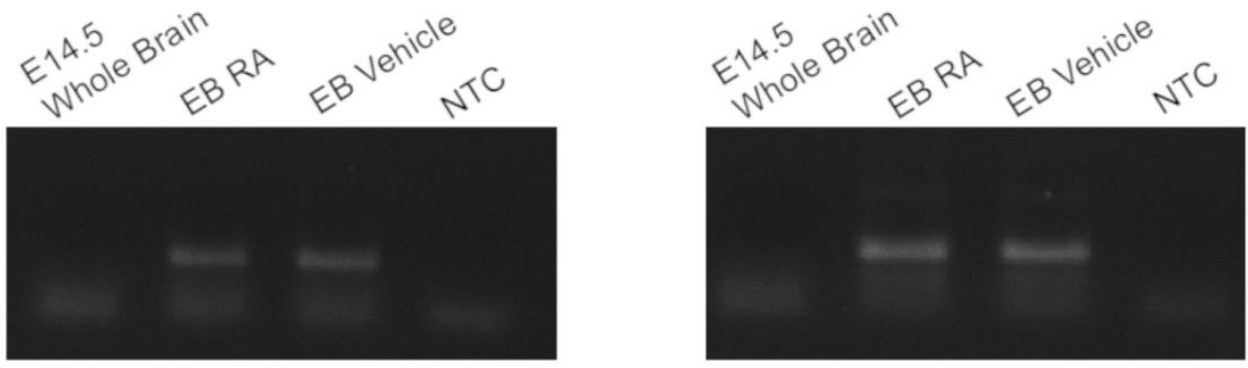

B

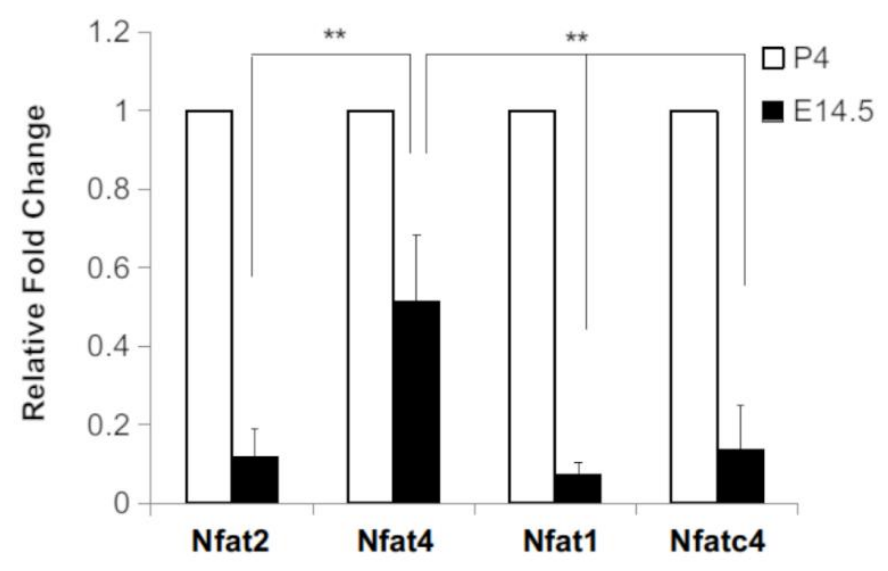


Table 1: PAX6 binding sites and corresponding EMSA probes used for Mrhl promoter, $3 k b$ upstream from TSS

\begin{tabular}{|c|c|c|c|c|c|c|}
\hline $\begin{array}{c}\text { Position } \\
(\mathbf{m m 9} \\
\text { genome) }\end{array}$ & Strand & Motif & Matched Sequence & p-value & $\begin{array}{c}\text { EMSA } \\
\text { Probes }\end{array}$ & $\begin{array}{c}\text { Site and } \\
\text { position } \\
\text { in bp }\end{array}$ \\
\hline $\begin{array}{l}\text { Chr8:885152 } \\
39-88515262\end{array}$ & + & $1-1$ & $\begin{array}{c}\text { TCTTAAATTATGCA } \\
\text { TCCTTCCGTG }\end{array}$ & 0.000321 & Probe 1 & $\begin{array}{c}\text { Site } 1 \\
(2904 \mathrm{bp})\end{array}$ \\
\hline $\begin{array}{l}\text { Chr8:885152 } \\
43-88515266\end{array}$ & + & $2-1$ & $\begin{array}{c}\text { AAATTATGCATCCT } \\
\text { TCCGTGCACC }\end{array}$ & $3.02 \mathrm{e}-05$ & Probe 1 & $\begin{array}{c}\text { Site } 1 \\
(2904 \mathrm{bp})\end{array}$ \\
\hline $\begin{array}{l}\text { Chr8:885168 } \\
67-88516890\end{array}$ & - & $1-3$ & $\begin{array}{c}\text { TTATCATTTTCTCCT } \\
\text { AGACTGATG }\end{array}$ & $8.95 \mathrm{e}-05$ & Probe 2 & $\begin{array}{c}\text { Site } 2 \\
(1276 \mathrm{bp})\end{array}$ \\
\hline $\begin{array}{l}\text { Chr8:885168 } \\
69-88516887\end{array}$ & - & $3-3$ & $\begin{array}{c}\text { TCATTTTCTCCTAGA } \\
\text { CTGATGA }\end{array}$ & $5.72 \mathrm{e}-05$ & Probe 2 & $\begin{array}{c}\text { Site } 2 \\
(1276 \mathrm{bp})\end{array}$ \\
\hline $\begin{array}{l}\text { Chr8:885174 } \\
71-88517489\end{array}$ & + & $4-1$ & $\begin{array}{c}\text { TAAAATTCTTCATG } \\
\text { TGTC }\end{array}$ & 0.000751 & Probe 3 & $\begin{array}{c}\text { Site } 3 \\
(672 \mathrm{bp})\end{array}$ \\
\hline $\begin{array}{l}\text { Chr8:885175 } \\
21-88517438\end{array}$ & - & $4-1$ & $\begin{array}{c}\text { AAAAAGTAACCACT } \\
\text { GCTC }\end{array}$ & 0.000869 & Probe 4 & $\begin{array}{c}\text { Site } 4 \\
(622 \mathrm{bp})\end{array}$ \\
\hline
\end{tabular}


bioRxiv preprint doi: https://doi.org/10.1101/2021.06.23.449546; this version posted June 23, 2021. The copyright holder for this preprint (which was not certified by peer review) is the author/funder. All rights reserved. No reuse allowed without permission.

\section{Supplementary File 1 (a SnapGene file)}

AAATATAAATATGTAAAATTCTGTATGAGGACAGTCATGGTGGCACATGCTTTTAATCCC AGCAAAGACAGAGGCTGAGTCAGGCAGAGCTTAGTGAGTTCAAGGTGACTCTGGTCTTGC TGTCAAATTATGGGCAGCCAGCGCTACATGTGAGACCTCGTGTGGTGATTGACTATTATG AAAATATCTCCTACTTTCGAAGAGACTAAAACTTTCACTGGATGTCACAGCCAGAGTTAA TAATAGAACTTGGAGTCACAGTTTAAGACTATTATCATACTGTGTGTTCAAACAGTTTTT CTCTTTCTTTCTTGTTCATTTGTTTTTGAGACAAGATCTCTCCATACATCCCTGGCTGT CCTGGAACTTACTCTGTAGACCAGGCTGTCTTCAAACTCAGAGAACTGCCTCCCTCTGCC TCGAGAGTCCTGGGACTAAAGACATGTGCCCACCATGCCCAGCCTCAACCTGTTCCTTTA GCCTGCCTTAAGGGGACAATGCAACAATCCACCTTACTTGCCTTGGATTTCCCTTGCCAT CAGCATTTACAACCTAAGCTAATGCACAACTGTAATCTTAAATTATGCATCCTTCCGTGC ACCTGACACATCCCAAATGAATGTATCATTTTTTGAAAGCAGAAAATACAGACATTGATA GCAACCTTCCCAAATGACTGAATATCTACCATAAATGCATAGTGTTGAACACATTTGGGT AGTTTGATAAACAATGATTCTTATAATACTATTTGTTATCTGGGTACTTTGGAGTCAGTA ACTTAATACCTCGTAACACTCTGTTAAAGATTTCTGAGTCTCCCAATCCTTCCTCATATG ATTCTGTGCTGTTCACAAAGACAAGATAAAGCCCTTTGTTAGTGATACACACCACACACA AACAAACACAGAGGGGGGGAGGGAGGGAGGGGAGAGAGAGAGAGAGAGAGAGAGAGAGAG AGAGAGAGAGATTGATTGATTGATTGATTGATTGATTCACAAGGCAGCCTCAGGCAAGAG CAAATTCAGACTCATACACTCAACATGCAGAGGATCAAAGACATGGGGAGCATGAAGTGG AGAACTCAAATATGGACTTGCTCTTGGTTAAGTAAAAAACCAAAGGGAAAGGCTAGCACC CTGACATGCTGGCTGGCTGGCTTGCTTTCAGTCAGTCAGTCTGTCTGTCTGTCTTTTCTT TCTATTACTTTTGGATTAATTCTATTATGTGCAAACTATTATTTTGTTTCAAAAAATAA AAATAAATTCTCTAGAAATTTCTTCCTGAAGATTAAGTACTCTGTGTGTGTGTGTGTGT GTGTGTGTGTGTGTGTGTGTCTTTGAGGAAGTGGTGCAGTGTGGTCTTTACATCATAAAA ATCTAGCCTGCCTCTTTAACTTCAACTATGGCCTTAAACAATTTAATCACTTTAAGCCTT TCCTTGTCTATTATATAGAAATGGCA ACTTTGÄCTACAGTGTCACAAATGAAAATGTGT CATACATTTTTTTAATAGGTATTTAGCTCATTTACATTTCCAATGCTATACCAAAAGTT CCCCATACCCACCCCCCCCACTCCCCTACCCACCCACTCCCCCTTTTTGGCCCTGGTGTT CCCCTGTACTGGGGCATATAAAGTTTGCAAGTCCAATGGACCTCTCTTTGCAGTGATGGC CGACTAGGCCATCTTTTGATACATATGCAGCTAGAGACAAGAGCTCCGGGGTACTGGTTA GTTCATAATGTTGTTCCACCTATAGGGTTGCAGTTCCCTTTAGTTCCTTGGGTGCTTTCT CTAGTTCCTCCATTGGGGGCCCTGTGGTCCATTCAATAGCTGACTGTGAGCATCCACTTC TGTGTTTGCTAGGCCCTGGCATAGTCTCACAAGAGACAGCTATATCTGGGTCCTTTCAGC AAAATCTTGCTAGTGTATGCAATGGTGTCAGTGTTTGGAAGCTGATTATGGGATGGATCT CTGGATATGGCAATCACTAGATGGTCCATCCTTTCGTCACACTTCCAAATTTTGTCTCTG TAACTCCTTCCATGGGTGTTTTGTTTCCTATTCTAAGAAGGGGCAAAGTGTCCACACTTT GGTCTTCTTTCTCTTGAGTTTAATGTGTCATACATTTTAAGAGCTCAATAAATATTATTT TTCATTTTATTTCAAATTGCATACTTAAGAACTGAGAAAAAATCATCAGTCTAGGAGAAA ATGATAAATTTACTATTGTTTTTAAGGAAATTACAACAGTTTAATTTTACCAAAGAATAT TAGGGAGCTAGATACTGGAGTGAAAGCCTGCTAACTCATGAGTGGCAGAGATAGCAACCC AGCTGATCTTCCACAGCTGATGTCCCACAAAGAGGCTCTTTGTTTATATAATCTAAAAAG GCCCTCAAACTGAATGCCCCAACTCTCTACTTCCTGTGTGTCTCTATCCTCCCTCCTGAC TTCCTCTTACACTCTATGGTGTTTTTTTTTTATGTCCACTCCCTATCAATTGGCAATTA GTCGGCCTCTACCTATGGTTGCCTTCATTTAATCCTGTTTACAATAAGCAGAAAGCTCTT GTATTAAAGGTGTGTGCTAGGGCTGAGCCACACCACAACTAGAAACAGGTTTTCCCAGTA

RARE AACAACACAATATCAGGGTTCACAGTGTGATCACACATCCTGAAACAGTTTACAAATACG TAGGCATATGGAAGCTTTCTTGTCTTGTGTTATAGCCTCATTGGTATCCACGTTTTTATA GTCGTTGACATATTCTTAATGCTCAATGACATGCTACATTATCTTTCTAAAATTCTTCAT GTGTCTGTGTATACCTCTTCATTTGTCTCCTTAGCAAGAGCAGTGGTTACTTTTTGTGTT TTTATGACAAAGTAACAGAGAAACAGTTTAAGGAAGGAAAGAAAGTTTCTTTTGGCTCAC AGATTAAGGGTACTGTTCATCCAAGGAGGGAGTGTGGCTGAGAGACCTCTCTAGCTGTGG

Meis 1 GCATCCTGTCAGAAACCTGGTCCCATTTCATTTGCACTCATGAAGAGGAAACAGATGGAG GCTAATTTCAGCTTCCTTTTTTCAATTTTCTTCTTCTTTGTCCTGAACTCCAGCCTATCT GATGGTGTTGCACACAGTCAGGGTGGATCTTCCTTCCTTCCTTCCTTTCTTTTTTTTTTT TTTTTTTTTTTTTTGGTTTTTAGACAGGGTTTCTCTGTATATCCCTGGCTGTCCTGGAA CTCACTTTGTAGACCAAGCTGGCCTTGAACTCAGAAATCCGCCTGCCTCTGCCTCCCGAG TGCTGGGATCAAAGGTGTGCGCCACCACTTAAAACTCTCTGGAAACACGGTCAGCATAAG GTGTGCTTTACCAGATAATCGCTAATCATTTTTACTCTAGACATTGGTCCTAATAGCAGC TGACCATACTCTGATGTTTATTGCTGTAAAATGCTGGCATCACATTTAAATCTATTAATG TGACTTG

\section{$2904 \mathrm{bp}$}

Motif 1-1

Motif 2-1

Underlined: Pax6

ChIP-Seq Read 1

\section{RARE}

\section{$1276 \mathrm{bp}$}

Motif 1-3

Motif 3-3

Underlined: $\quad$ Pax6

ChIP-Seq Read 2

Motif 4-1

Underlined: Pax6

ChIP-Seq Read 3

NEAT BS2

NFAT BSI 


\section{Supplementary File 2}

\section{Antibodies}

\begin{tabular}{|c|c|c|}
\hline Name of antibody & Company & Catalog No. \\
\hline Anti-H3 & Abcam & ab46765 \\
\hline Anti-NESTIN & Abcam & ab14545 \\
\hline Anti-TUJ1 & Abcam & ab12209 \\
\hline Anti-H3K4me3 & Abcam & ab8915 \\
\hline Anti-NICD & Abcam & ab5790 \\
\hline Anti-PAX6 & Abcam & Ab6302 \\
\hline Anti- $\beta$-catenin & Abcam & ABE2864 \\
\hline Anti-MEIS1 & Millipore & 2569 \\
\hline Anti-TCF4 & Cell signaling technology & PA5-79734 \\
\hline Anti-NFAT4/NFATc3 & Invitrogen & \\
\hline
\end{tabular}

\section{Primer and Oligo Sequences}

\section{qRT-PCR primers}

\begin{tabular}{|l|l|l|}
\hline Gene Name & Forward Primer (5' to 3') & Reverse Primer (5' to 3') \\
\hline Nestin & GTCGCTTAGAGGTGCAGCAG & TTCCAGGATCTGAGCGATCT \\
\hline \multirow{2}{*}{ Pax6 } & TCCAGGTGCTGGACAATGAA & GCTTTTCGCTAGCCAGGTTG \\
\cline { 2 - 3 } & CGGCTTCCCACAACTCTATC & ACCGCCCTTGGTTAAAGTCT \\
\hline \multirow{2}{*}{ Tuj1 } & TTGCGGCTGCTTTCCTTTTC & CTGCGAAGCACGATCAAAGG \\
\hline GFAP & TGAGGCCTCCTCTCACAAGT & CCAGCACCACTCTGACCAAA \\
\hline Hes5 & CACGAACGAGTCCCTAGAGC & GTGGCCTTCTGACACGGATT \\
\hline \multirow{2}{*}{ Mrhl } & GAGATGCTCAGTCCCAAGGAG & GCGAAGGCTTTGCTGTGTTT \\
& TGAGGACCATGGCTGGACTCT & AGATGCAGTTTCCAATGTCCAAAT \\
\cline { 2 - 3 } & CTGCACACACACAAACACACA & AGGGTTCTCTGTCCTGACCT \\
\hline
\end{tabular}




\begin{tabular}{|l|l|l|}
\hline FoxG1 & GGCAAGGGCAACTACTGGAT & CGTGGTCCCGTTGTAACTCA \\
\hline En1 & TCCTACTCATGGGTTCGGCT & CTGGAACTCCGCCTTGAGTC \\
\hline Gbx2 & CAACTTCGACAAAGCCGAGG & TGACTCGTCTTTCCCTTGCC \\
\hline Nfatc1/NFAT2 & ACCGATAGCACTCTGGACCT & GTCGGGGAAAGAGACTTGGG \\
\hline Nfatc3/NFAT4 & TCAGTCATGCACCAGCCTTT & AGGTGGGGTTTGCACAGAAT \\
\hline Nfatc2/NFAT1 & CCAAGACGAGCTGGACTTTTC & GCATCAGTTCGTGGGATGGA \\
\hline Nfatc4 & TGGTTATAGCACACCCGCTC & CTCAGGAGGTAAGGGGTGGA \\
\hline$\beta$-actin & AGGTCATCACTATTGGCAACG & TACTCCTGCTTGCTGATCCAC \\
\hline
\end{tabular}

\section{ChIP primers}

\begin{tabular}{|l|l|l|}
\hline Gene Name & Forward Primer (5' to 3') & Reverse Primer (5' to 3') \\
\hline $\begin{array}{l}\text { Mrhl Pax6 } \\
\text { ChIP Site 1 }\end{array}$ & TCCACCTTACTTGCCTTGGA & CAGTCATTTGGGAAGGTTGCT \\
\hline $\begin{array}{l}\text { Mrhl Pax6 } \\
\text { ChIP Site 2 }\end{array}$ & GGTCTTCTTTCTCTTGAGTTTAATGT & GGGTTGCTATCTCTGCCACT \\
\hline $\begin{array}{l}\text { Mrhl Pax6 } \\
\text { GiP Site }\end{array}$ & TTCATGTGTCTGTGTATACCTCTTCA & TTTCCTTCCTTAAACTGTTTCTCTG \\
\hline $\begin{array}{l}\text { Mrhl Proximal } \\
\text { Promoter } \\
\text { (Histone } \\
\text { ChIP) }\end{array}$ & GAACTCCAGCCTATCTGATGGT & GCGATTATCTGGTAAAGCACACC \\
\hline $\begin{array}{l}\text { Actin ChIP } \\
\text { Mrhl Mesis1 }\end{array}$ & TACATCCAAGGAGGGAGTGT & \\
and NFAT4 & & GGCTGGAGTTCAGGACAAAG \\
BS2 ChIP & & \\
\hline $\begin{array}{l}\text { Mrhl TCF4 } \\
\text { and NFAT4 }\end{array}$ & AGAAATCCGCCTGCCTCT & GATGCCAGCATTTTACAGCA \\
\hline
\end{tabular}

\section{Cloning primers}




\begin{tabular}{|l|l|l|}
\hline Gene Name & Forward Primer (5' to 3') & Reverse Primer (5' to 3') \\
\hline Mrhl & CTAGCTAGCTAGAAACTG & \\
$1.25 \mathrm{~kb} \_N h e I$ & AATGCCCCAACTCTC & \\
\hline Mrhl & CTAGCTAGCTAGCTCTT & \\
\hline Mrhl & GAGTTTAATGTGTCATAC & \\
$3.25 \mathrm{~kb}$ KpnI & TGGGTACCCCCTCAACCT & \\
\hline $\begin{array}{l}\text { Mouse Pax6 } 6 \text { CCCAAGCTTATGCAGAACAGTCACA } \\
\text { Cloning }\end{array}$ & GCGGAG & GGGGTACCTTACTGTAATCGAGGCCA \\
\hline $\begin{array}{l}\text { Mouse } \\
\text { Pax6(5a) }\end{array}$ & CCCAAGCTTATGCAGAACAGTCACA & GGGGTACCTTACTGTAATCGAGGCCA \\
Cloning & & GTACTG \\
\hline
\end{tabular}

\section{EMSA oligos (5' to 3'):}

\section{Site 1:}

Probe 1_F: CTGTAATCTTAAATTATGCATCCTTCCGTGCACCTGACAC

Probe 1_R: GTGTCAGGTGCACGGAAGGATGCATAATTTAAGATTACAG

\section{Site 2:}

Probe 2_F: AGAAAAAATCATCAGTCTAGGAGAAAATGATAAATTTACT

Probe2_R: AGTAAATTTATCATTTTCTCCTAGACTGATGATTTTTTCT

Site 3:

Probe 3_F: CATTATCTTTCTAAAATTCTTCATGTGTCTGTGTATACCTC

Probe 3_R: GAGGTATACACAGACACATGAAGAATTTTAGAAAGATAATG

\section{Site 4:}

Probe 4_F: TCTCCTTAGCAAGAGCAGTGGTTACTTTTTGTGTTTTTAT

Probe 4_R: ATAAAAACACAAAAAGTAACCACTGCTCTTGCTAAGGAGA

\section{Positive control for Pax6:}

P6CON_F: GGATGCAATTTCACGCATGAGTGCCTCGAGGGATCCACGTCGA

P6CON_R: TCGACGTGGATCCCTCGAGGCACTCATGCGTGAAATTGCATCC 